Old Dominion University

ODU Digital Commons

2001

\title{
Hydrogeological Characterization of the South Oyster Bacterial Transport Site Using Geophysical Data
}

\author{
Susan S. Hubbard \\ Jinsong Chen \\ John Peterson \\ Ernest L. Majer \\ Kenneth H. Williams
}

See next page for additional authors

Follow this and additional works at: https://digitalcommons.odu.edu/oeas_fac_pubs

Part of the Ecology and Evolutionary Biology Commons, Fresh Water Studies Commons, and the Water Resource Management Commons

\section{Original Publication Citation}

Hubbard, S. S., Chen, J. S., Peterson, J., Majer, E. L., Williams, K. H., Swift, D. J., . . Rubin, Y. (2001). Hydrogeological characterization of the South Oyster bacterial transport site using geophysical data. Water Resources Research, 37(10), 2431-2456. doi:10.1029/2001wr000279

This Article is brought to you for free and open access by the Ocean \& Earth Sciences at ODU Digital Commons. It has been accepted for inclusion in OES Faculty Publications by an authorized administrator of ODU Digital Commons. For more information, please contact digitalcommons@odu.edu. 


\section{Authors}

Susan S. Hubbard, Jinsong Chen, John Peterson, Ernest L. Majer, Kenneth H. Williams, Donald J. Swift, Brian Mailloux, and Yoram Rubin 


\title{
Hydrogeological characterization of the South Oyster Bacterial Transport Site using geophysical data
}

\author{
Susan S. Hubbard, ${ }^{1}$ Jinsong Chen, ${ }^{2}$ John Peterson, ${ }^{1}$ Ernest L. Majer, ${ }^{1}$ Kenneth H. Williams, ${ }^{1}$ \\ Donald J. Swift, ${ }^{3}$ Brian Mailloux, ${ }^{4}$ and Yoram Rubin ${ }^{2}$
}

\begin{abstract}
A multidisciplinary research team has conducted a field-scale bacterial transport study within an uncontaminated sandy Pleistocene aquifer near Oyster, Virginia. The overall goal of the project was to evaluate the importance of heterogeneities in controlling the field-scale transport of bacteria that are injected into the ground for remediation purposes. Geochemical, hydrological, geological, and geophysical data were collected to characterize the site prior to conducting chemical and bacterial injection experiments. In this paper we focus on results of a hydrogeological characterization effort using geophysical data collected across a range of spatial scales. The geophysical data employed include surface ground-penetrating radar, radar cross-hole tomography, seismic cross-hole tomography, cone penetrometer, and borehole electromagnetic flowmeter. These data were used to interpret the subregional and local stratigraphy, to provide highresolution hydraulic conductivity estimates, and to provide information about the log conductivity spatial correlation function. The information from geophysical data was used to guide and assist the field operations and to constrain the numerical bacterial transport model. Although more field work of this nature is necessary to validate the usefulness and cost-effectiveness of including geophysical data in the characterization effort, qualitative and quantitative comparisons between tomographically obtained flow and transport parameter estimates with hydraulic well bore and bromide breakthrough measurements suggest that geophysical data can provide valuable, high-resolution information. This information, traditionally only partially obtainable by performing extensive and intrusive well bore sampling, may help to reduce the ambiguity associated with hydrogeological heterogeneity that is often encountered when interpreting field-scale bacterial transport data.
\end{abstract}

\section{Introduction}

A multidisciplinary research team has conducted a fieldscale bacterial transport study within an uncontaminated sandy Pleistocene aquifer near Oyster, Virginia. The study is part of the Natural and Accelerated Bioremediation Research (NABIR) program of the Department of Energy. Bioremediation, the use of microorganisms that can degrade organic wastes or immobilize inorganic contaminants in the subsurface, is among the many technologies that are currently being evaluated by researchers in the scientific community as a treatment approach for contaminated subsoils and groundwater. Although bioremediation is considered a viable technique, microbial transport in the presence of complex subsurface hydrogeological and geochemical heterogeneities is not well understood. Although the physical heterogeneity of aquifer sediments has been recognized as a key control on microbial

\footnotetext{
${ }^{1}$ Earth Science Division, Lawrence Berkeley National Laboratory, Berkeley, California.

${ }^{2}$ Department of Civil and Environmental Engineering, University of California, Berkeley, California.

${ }^{3}$ Department of Ocean, Earth and Atmospheric Sciences, Old Dominion University, Norfolk, Virginia.

${ }^{4}$ Department of Geosciences, Princeton University, Princeton, New Jersey.

Copyright 2001 by the American Geophysical Union.

Paper number 2001WR000279.

0043-1397/01/2001WR000279\$09.00
}

transport behavior at the field scale [Harvey et al., 1993; Bales et al., 1995, 1997; Natch et al., 1996], no study to date has acquired dense enough characterization data in tandem with a field-scale bacterial transport experiment to enable investigation of the extent of the control.

A key focus of the Oyster project is to evaluate the relative importance of hydrogeological and chemical heterogeneities in controlling bacterial transport at the field scale [DeFlaun et al., 1997]. This focus includes addressing what level of characterization is necessary to predict field-scale bacterial transport, as well as addressing scaling issues associated with laboratory and field-based data. This in situ bacterial transport investigation is the first of its kind and involved extensive characterization using hydrological, geochemical, geological, and geophysical data followed by field-scale chemical and bacterial tracer tests. This study focuses on the hydrogeological characterization performed at the South Oyster Site using geophysical data. Other manuscripts present different facets of the investigation, including the design of the transport experiment [Scheibe et al., 2001], a microbial tracking technology [Johnson et al., 2001], investigations of the influences of physical heterogeneity on field-scale bacterial transport [Johnson et al., 2001], the influence of sedimentary facies type on bacterial transport at the core scale [Fuller et al., 2000a], and characterization of the microbial strain injected during the transport experiment [Fuller et al., 2000b].

The South Oyster Site is located on Virginia's Eastern Shore Peninsula (Figure 1a). The subsurface of the South Oyster Site 

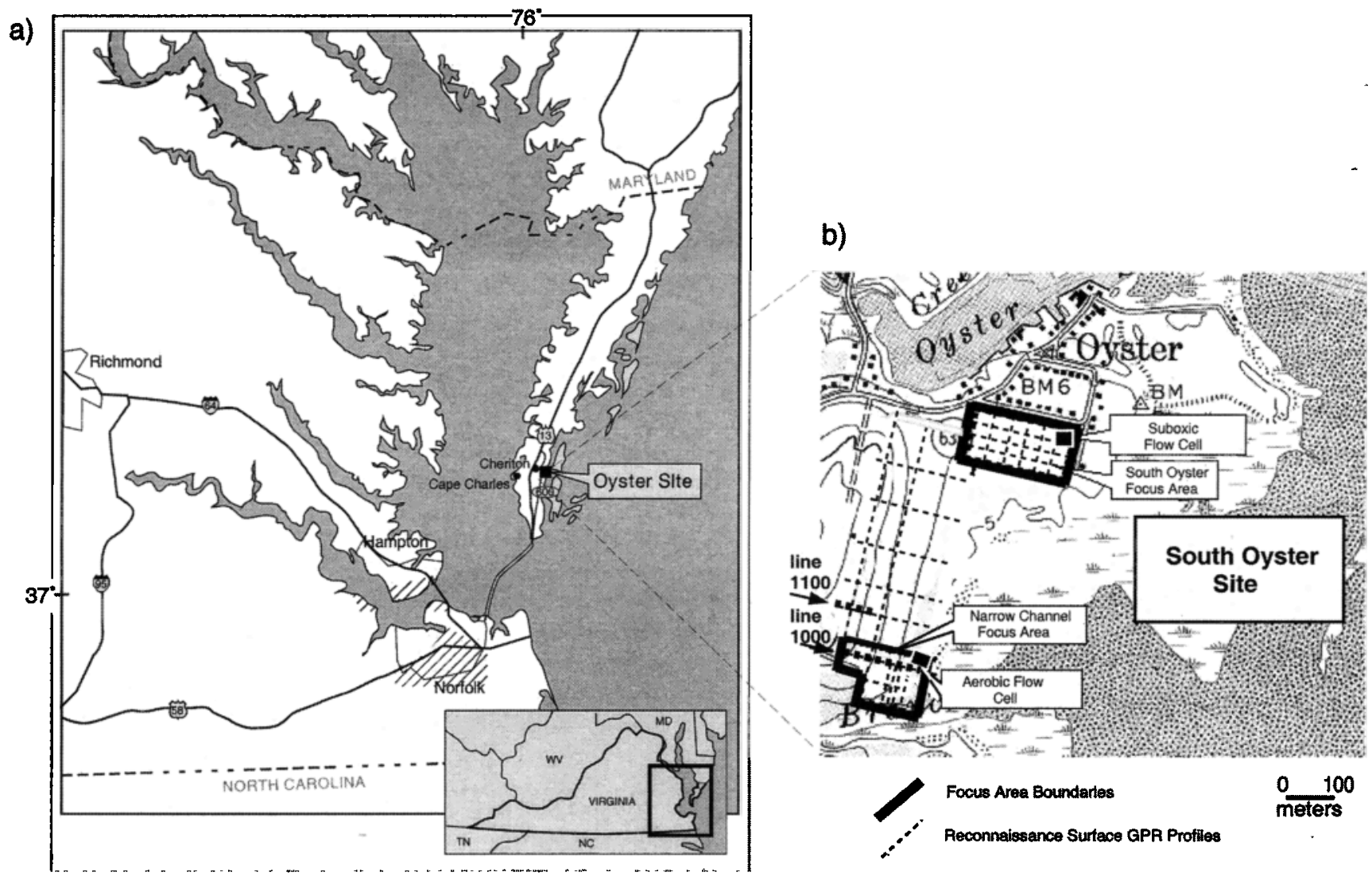

Figure 1. (a) Location map of the South Oyster Site of Virginia's Eastern Shore Peninsula. (b) Focus areas at the South Oyster Site including the Narrow Channel Focus Area and associated aerobic flow cell and the South Oyster Focus Area and associated suboxic flow cell. The location of the reconnaissance groundpenetrating radar data grid is shown by the dashed lines. Thick dashed lines annotate the locations of ground-penetrating radar (GPR) lines 1100 and 1000, which are interpreted as shown in Plate 2.

consists of unconsolidated to weakly indurated, late Pleistocene sands and pebbly sediments deposited in a marine shoreface depositional environment. The upper 5-9.5 $\mathrm{m}$ of the South Oyster Site study area consists of the Wachapreague Formation, which was deposited in a shallow, open marine to back barrier environment, north of the tide-dominated mouth of the Chesapeake Bay [Mixon, 1985]. The formation wedges out in a landward direction against the Mappsburg scarp, a geomorphic feature that extends the length of the Eastern Shore Peninsula. Below this formation and behind the scarp lies the older Butlers Bluff member of the Nassawadox Formation, which was deposited in a shoreface setting. The Butlers Bluff member is underlain by the Pliocene Yorktown Formation, an aquitard that serves as the lower boundary for our subsurface study volume. The water table is located at approximately 2-3 $\mathrm{m}$ below ground surface (BGS); this study focuses primarily on the saturated section between the depths of 3 and $9.0 \mathrm{~m}$ BGS, or approximately $0-6.0 \mathrm{~m}$ below mean sea level (msl).

The South Oyster Site consists of two focus areas: the South Oyster Focus Area and the Narrow Channel Focus Area (Figure 1b). These two focus areas were designated on the basis of their groundwater chemistry, level of geological heterogeneity, and position in the subregional stratigraphic section as will be discussed in section 3. In general, the geology at the Narrow Channel Focus Area is less complex than that of the South Oyster Focus Area. The Narrow Channel Focus Area sedi- ments are composed of predominantly clean sand with some gravel and silty sand, whereas the South Oyster Focus Area has peat layers and clayey silts, in addition to the sands and gravelly sand. The Narrow Channel Focus Area is situated within a primarily aerobic portion of the aquifer, while the groundwater conditions are primarily suboxic at the South Oyster Focus Area.

Chemical and bacterial transport experiments have been executed at both the Narrow Channel and South Oyster Focus Areas within what are termed the "aerobic flow cell" and the "suboxic flow cell," respectively. Conservative chemical and bacterial tracer tests were initially performed within the aerobic flow cell at the Narrow Channel Focus Area in 1999, and similar transport experiments were conducted at the (more geologically complex) suboxic flow cell within the South Oyster Focus Area in 2000. In this study, we present hydrogeological interpretations based on geophysical data from the large scale to the more detailed spatial scale. The interpretations at the finer spatial scale concentrate on the data collected within the Narrow Channel Focus Area; detailed characterization of the South Oyster Focus Area is currently in progress following the same approach that was developed for the Narrow Channel Focus Area and that is presented in this study.

The aerobic flow cell layout within the Narrow Channel Focus Area is shown in Figure 2a. The groundwater and tracer injection well is $\mathrm{B} 2$, and the groundwater extraction wells are located $\sim 20 \mathrm{~m}$ downgradient from B2. The groundwater in- 


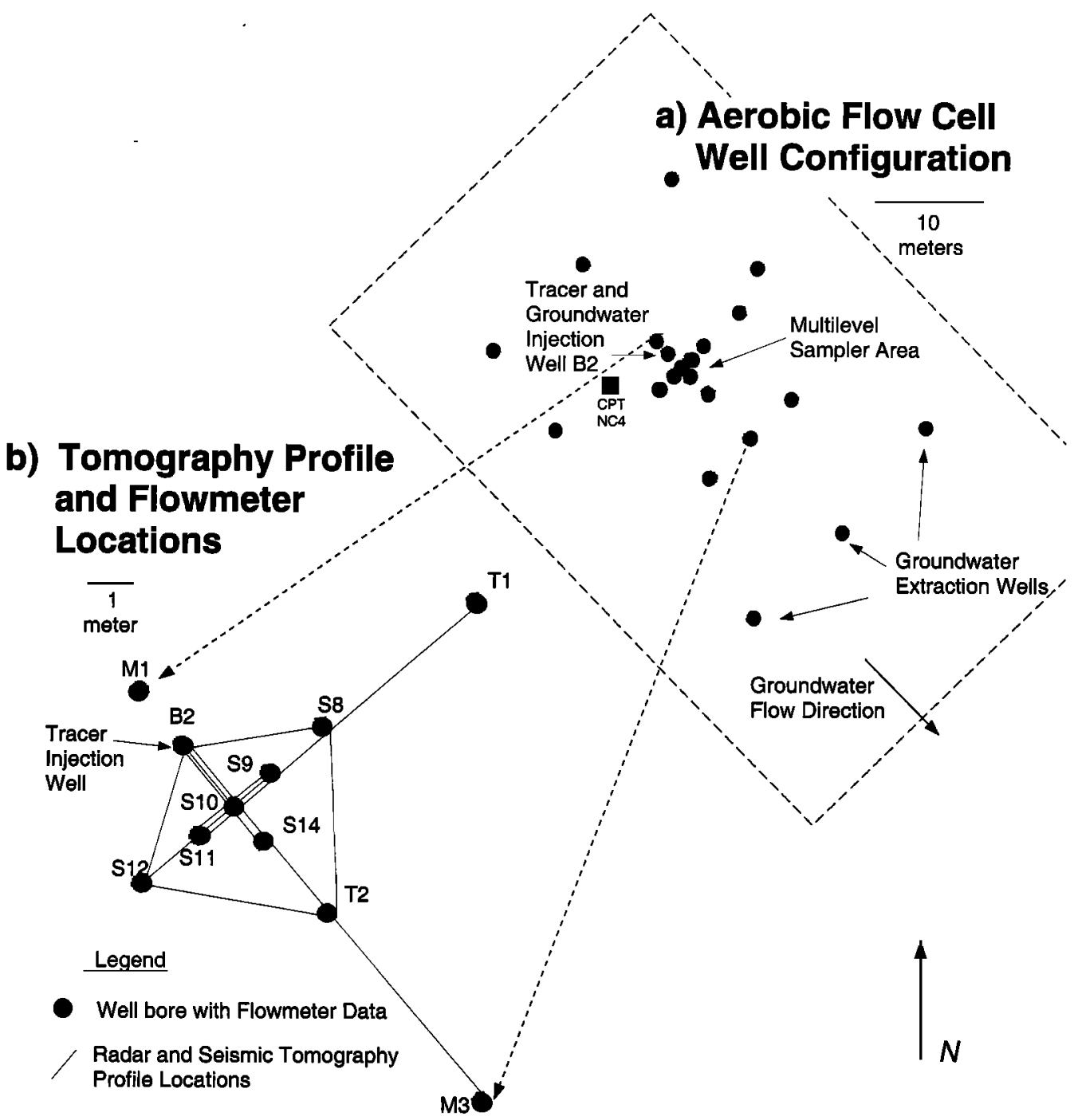

Figure 2. (a) Narrow Channel Focus Area aerobic flow cell geometry, well locations, and location of cone penetrometer (CPT) NC4, which is shown in Figure 5. (b) Approximate locations of high-resolution tomographic profiles and flowmeter data collected within the aerobic flow cell in the vicinity of the multilevel sampler array. Other Oyster publications may use an alternate well-naming convention, as described in Table 1.

jection and extraction wells were designed to set up a steady state flow field in the saturated section before and during the injection experiments. In October of 1999, bromide tracers and a selectively grown, indigenous strain of bacteria (Comamonas sp.) were injected into the saturated study section at selected depths. Twenty-four multilevel samplers were installed within a polygonal-shaped area, bordered at the upgradient end by tracer injection well $\mathrm{B} 2$ and by the downgradient well M3 (shown in Figure 2b), to detect the passage of the chemical and bacterial tracers over time. Fuller et al. [2000b] describe the bacterial strain used for the injection, and Johnson et al. [2001] describe the transport experiments in more detail. Several other facets of the experiment were also presented in a special session devoted to field-scale bacterial transport experiments, given in Eos Transactions of the American Geophysical Union, 81(48), F180 and F183, 2000.

Geophysical data were collected across a range of spatial scales at the Narrow Channel Focus Area prior to conducting the transport experiments. The characterization information obtained from the geophysical data was used for a variety of applications. At the largest spatial scale, reconnaissance geophysical data were initially used to delineate the stratigraphic relationships at the South Oyster Site and subsequently to choose locations for the individual focus areas within the site. More detailed geophysical data were then used to position the flow cell within the Narrow Channel Focus Area, as well as to delineate zones for positioning the chemical and bacterial tracer injection and sampling instruments. At this detailed scale, high-resolution geophysical data were used to provide estimates of hydraulic conductivity and its spatial correlation parameters to assist the numerical bacterial transport modeling effort, to help in the interpretation of the bacterial breakthrough data, and to estimate the bromide plume spatial moments.

Several other studies have also investigated the use of geophysical data to aid hydrological studies, including those of Daily and Ramirez [1984], Daily et al. [1992], Hyndman et al. [1994, 2000], Hyndman and Gorelick [1996], Poeter et al. [1997], 
and Eppstein and Dougherty [1998]. These studies suggest that high-resolution geophysical data can be useful for estimating hydrological properties as well as for delineating the geometry of the aquifer at locations within the study volume that are traversed by the geophysical profiles. A few investigations have also focused on extracting spatial correlation information from geophysical data, including those of Knight et al. [1996, 1997], Rea and Knight [1998], and McKenna and Poeter [1995].

Several different estimation methodologies have also been developed by the some of the authors for use with joint geophysical-hydrological data [e.g., Rubin et al., 1992; Copty et al., 1993; Copty and Rubin, 1995; Hubbard et al., 1997, 1999; Ezzedine et al., 1999; Chen et al., 2001]. Although the key focus of this paper is to present a complete and multiscaled characterization at a bacterial transport study site using geophysical data, as some of our estimation methods are invoked in the characterization presented in this study, they are briefly summarized in this paper for completeness. Our estimation methods differ from some of those cited above in that we work within a stochastic framework, where the hydrogeological variables are treated as space random functions. As the hydrogeological parameters are estimated through their moments, our approaches permit quantification of the estimation uncertainty and also facilitate use of the estimate information within stochastic simulation routines used for producing different realizations of a flow and transport domain. Our estimation procedures rely on the correlation between the hydrogeological parameter of interest and the geophysical attributes, either developed at the site, which is preferable, or borrowed from literature. The Bayesian method allows us to incorporate prior information and to condition the images sequentially as more data become available. This approach allows us to systematically fuse multiple sources of information and to account for complex and nonlinear petrophysical models that sometimes exist between the geophysical and hydrological variables. As the Bayesian method incorporates the cross correlations between different types of data, the treatment of data redundancy is systematic. Last, our approaches call for estimation of the space random function models as a function of their measurement support, not just of point estimation at a single measurement support scale. This leads to a more comprehensive treatment of uncertainty, because it addresses the problem of integration of data having different measurement support scales and also accounts for parametric uncertainty.

Section 2 of the paper describes the available data used in the interpretation, including surface radar, cross-well tomographic radar, cross-well tomographic seismic, cone penetrometer, and flowmeter measurements. In the following sections, we present our interpretation based on these data from the larger to the more detailed spatial scales. Our interpretation of the subregional and local stratigraphy, based on surface ground-penetrating radar profiles integrated with cone penetrometer information, is presented in section 3 . In section 4, we review a methodology to incorporate tomographic geophysical data into a hydraulic conductivity estimation routine and apply this methodology to the Oyster data. In section 5, a procedure to estimate the spatial correlation function for hydraulic conductivity using the interpreted cross-well tomographic information is described and applied. To test the validity of using tomographic data for parameter estimation, we compare tomographically obtained plume spatial moments with bromide breakthrough observations in section 6 . This study highlights how geophysical data can be used across a range of spatial scales to help with the design of field experiments, for constraining numerical flow and transport models, and for helping to understand field-scale bacterial transport processes.

\section{Description of Geophysical Tools}

The geophysical tools available for characterization at the South Oyster Site include surface ground-penetrating radar (GPR), cross-well tomographic radar and seismic data, cone penetrometer (CPT) tests, and borehole flowmeter logs. Figure 3 schematically illustrates these tools, showing the resolution and fraction of aquifer volume sampled associated with each of the characterization methods. Figure 3 also relates the scale of the geophysical characterization tools used at the South Oyster Site to the traditional hydrological tools of core analysis and well tests. This chart illustrates how geophysical data can help to bridge the information gap that exists when only conventional hydrogeological tools of core analysis and well test data are used for characterization. In addition to the characterization tools indicated in Figure 3, we also utilized reconnaissance surface GPR data collected over a much larger spatial scale. In sections $2.1-2.5$, we discuss the mechanics of each of these geophysical sampling methods and describe the data sets collected at the South Oyster Site.

\subsection{Surface Ground-Penetrating Radar (GPR)}

GPR is a geophysical tool that has become increasingly popular as researchers across a variety of disciplines strive to better understand near-surface conditions. GPR uses electromagnetic energy at frequencies of $50-1500 \mathrm{MHz}$ to probe the subsurface. At these frequencies, dielectric properties, the separation (polarization) of opposite electric charges within a material subjected to an external electric field, dominate the electrical response [Davis and Annan, 1989]. In general, GPR performs better in unsaturated coarse- or moderately coarse textured soils; GPR performance is often poor in electrically conductive environments such as those dominated by clays.

A GPR system consists of an impulse generator, which repeatedly sends an impulsive signal of fixed voltage and frequency spectrum to a transmitting antenna. A signal propagates from the transmitting antenna through the earth and is reflected, scattered, and attenuated by subsurface dielectric contrasts; the receiving antenna subsequently records the modified signal. Dielectric constants $\kappa$ vary as a function of material saturation, porosity, material constituency, temperature, and pore fluid composition. The most common GPR acquisition mode is surface common-offset reflection, which involves collecting one trace per surface location from a transmitterreceiver antenna pair as the pair moves along the ground surface, as shown in Figure 4a. Data collected in this mode are typically displayed as wiggle-trace profiles, with distance on the horizontal axis and arrival time (which can be converted to depth using electromagnetic wave velocity information) on the vertical axis. The variations in arrival time, amplitude, and phase of the signals indicate subsurface variations in electromagnetic properties. Surface GPR profiles are useful for investigating variations in physical and hydrological properties and for inferring the stratigraphy and structural geology along two-dimensional profiles or within a pseudo three-dimensional grid composed of several two-dimensional profiles.

The surface GPR data at the South Oyster Site were col- 


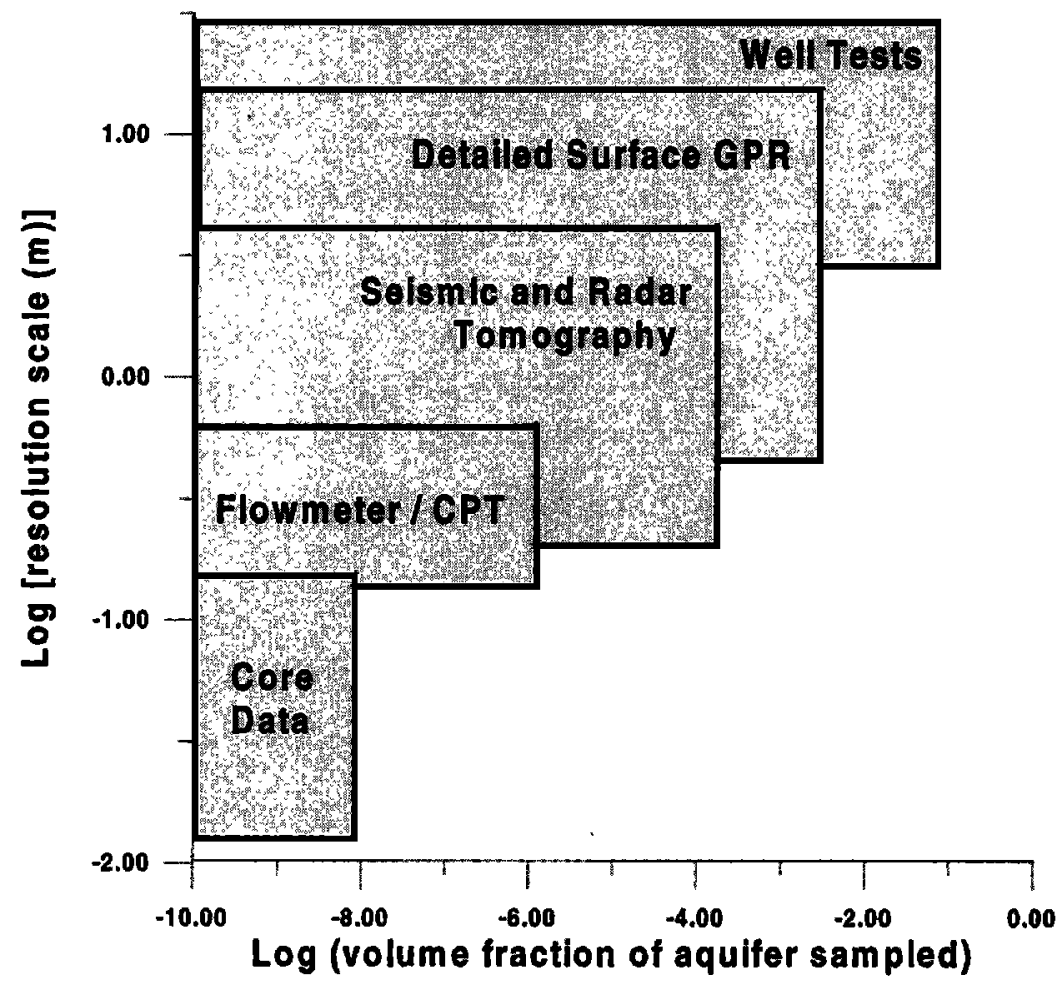

Figure 3. Comparison of resolution and fraction of aquifer volume sampled using different characterization tools at the Narrow Channel Focus Area. Geophysical data help to bridge the information gap in terms of both resolution and fraction of aquifer volume sampled between the more conventional hydrological sampling techniques of core analysis and well tests.

lected using a PulseEKKO 100 system with 100 and $200 \mathrm{MHz}$ central frequency borehole antennas. Radar data were collected at two spatial scales within what are called the "reconnaissance" and "detailed" data grids. The total traverse distance of the reconnaissance GPR data, collected at a minimum line spacing of $15 \mathrm{~m}$, was $4350 \mathrm{~m}$. The dashed lines in Figure $1 \mathrm{~b}$ show the locations of these reconnaissance lines, which were used (as will be described in section 3) to interpret the subregional stratigraphy and, subsequently, to help place the focus areas within the South Oyster Site. Once the focus areas were selected, a detailed grid of 42 lines traversing a total of $1680 \mathrm{~m}$ at $2 \mathrm{~m}$ line spacing was collected within the Narrow Channel Focus Area.

\subsection{Radar Tomography}

In addition to surface GPR data acquisition, tomographic radar data were also collected within the aerobic flow cell. A typical cross-hole tomographic geometry consists of two vertical boreholes separated by an interwell region of interest. Transmitting and receiving antennas are located in separate boreholes. Direct energy from a transmitting antenna in one borehole is recorded by instruments attached to a receiving antenna located in the other borehole. The transmitter position is changed and the recording is repeated until both the transmitter and the receiver have occupied all possible positions within the two boreholes. The direct electromagnetic wave travel times between all transmitter and receiver positions, as well as the amplitude of the direct arrivals, are obtained from the recorded data. For our applications, energy is assumed to travel along straight ray paths, as shown in Figure 4b. Peterson [1986] and Bregman et al. [1989] suggest that this assumption is valid for seismic tomographic applications when the velocity variations are less than $\sim 20 \%$. Straight-ray inversion techniques are similarly considered valid for radar tomographic data collected in regions of low to moderate velocity contrasts [Peterson, 2001]. The interwell area is then discretized into a grid composed of cells or pixels, and inversion algorithms are used to transform the recorded travel time and amplitude information into estimates of electromagnetic wave slowness (the reciprocal of velocity) and attenuation at each pixel, respectively.

Eleven tomographic radar profiles were collected near the tracer injection borehole within the aerobic flow cell; the locations of the tomographic profiles are shown in Figure $2 b$. The nomenclature of these tomographic wells was modified upon installation of multilevel samplers. This manuscript utilizes the most recent nomenclature; because other Oyster Site research publications may use the older nomenclature, a tabulation of both naming convention schemes is given in Table 1 . The radar tomographic data were collected using a PulseEKKO 100 system with 100 and $200 \mathrm{MHz}$ central frequency antennas and a transmitter and receiver spacing in the well bores of $0.125 \mathrm{~m}$. The first arrival travel times and amplitudes were picked for each transmitter-receiver location in each well pair, amounting to analysis of a total of approximately 13,200 traces. The electromagnetic wave velocity estimates were obtained by inverting the picked radar travel times for slowness values and then taking the reciprocal of the slowness values to obtain velocity estimates. The attenuation values were obtained from inverting the radar amplitude data. Inversion was performed using an algebraic reconstruction technique [Peterson et al., 1985; Peterson, 2001] using discretization 

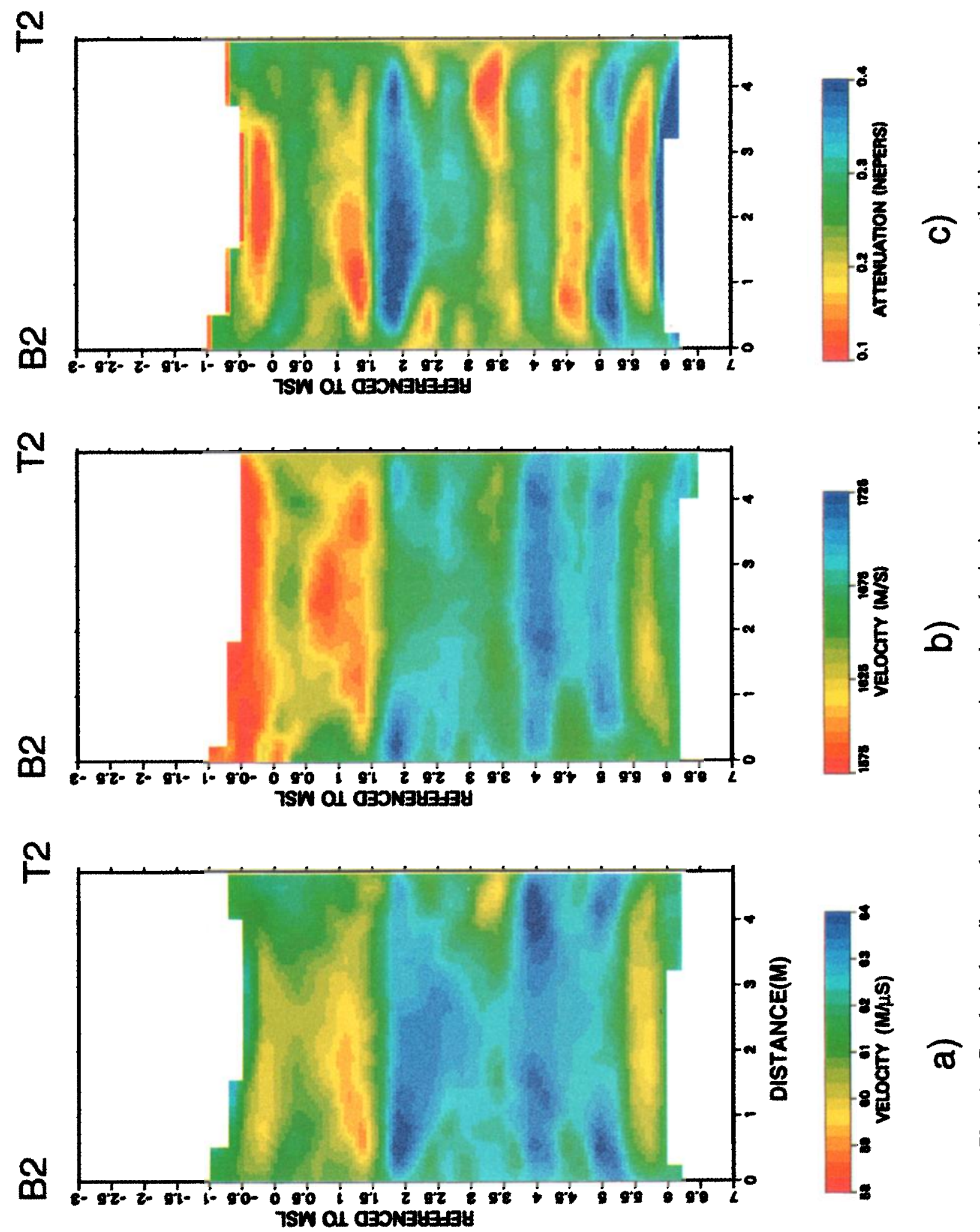

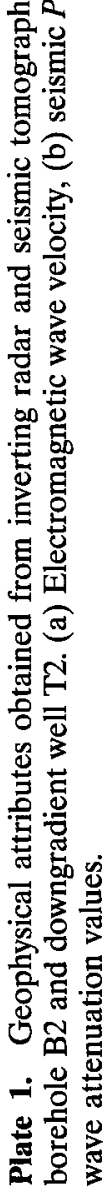
(wi) HId $\exists O$ 
a)



b)

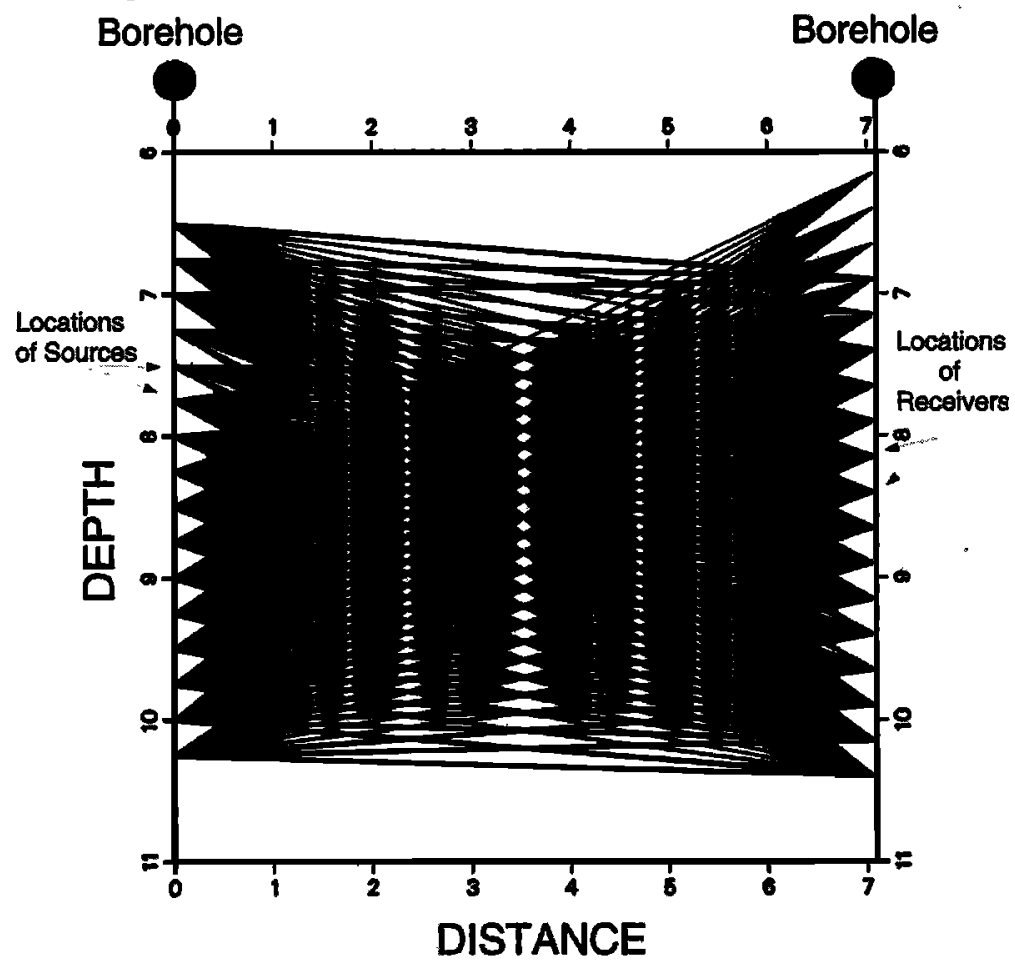

Figure 4. Acquisition geometries used to collect geophysical data at the Narrow Channel Focus Area. (a) Surface radar common-offset geometry showing reflection of an electromagnetic wave at a subsurface discontinuity, (b) tomographic borehole geometry used for both radar and seismic acquisition. The straight lines represent the assumed paths of the radar or seismic signals.

of $0.25 \mathrm{~m}$ in both the horizontal and vertical directions. An assumption inherent in this inversion routine is that the rays travel within the two-dimensional plane between the boreholes along straight rays. No well bore constraints, smoothing, or assumptions about anisotropy were imposed during the tomographic data inversion process. Source and receiver corrections were performed, however, which attempt to dampen geophysical responses at the borehole due to disturbances such as washouts or sloughing. Although effective at removing spurious events at the borehole locations due to localized borehole effects, these static corrections also tend to remove geophysical measurement fluctuations in general and often result in geophysical attribute values at the borehole locations that have less variability than those values obtained for the area between well bores [Gritto et al., 1997; Vasco et al., 1996].

Plates 1a and 1c display images of the radar velocity and attenuation values, respectively, obtained from this inversion
Table 1. Well Nomenclature Schemes for the Wells at the Narrow Channel Focus Area ${ }^{a}$

\begin{tabular}{cc}
\hline Nomenclature 1 & Nomenclature 2 \\
\hline T1 & T1 \\
T2 & S8 \\
S7 & S9 \\
S9 & S10 \\
S11 & S11 \\
T3 & S12 \\
S18 & S14 \\
S24 & T2 \\
B2 & B2 \\
M1 & M1 \\
M3 & M3
\end{tabular}

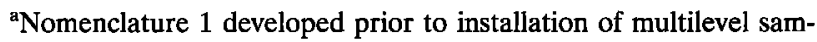
plers, and nomenclature 2 developed after sampler installation. In this manuscript, we follow nomenclature 2 as illustrated in Figure 2. 
process using data collected between the tracer injection well $\mathrm{B} 2$ and well $\mathrm{T} 2$, which is $4.67 \mathrm{~m}$ downgradient along the expected injectate plume centerline (see Figure $2 b$ ). The images presented are contoured displays of the $0.25 \mathrm{~m} \times 0.25 \mathrm{~m}$ geophysical attribute pixel values; these images were created merely by interpolating between the centers of each pixel with no correlation structure imposed. The artifacts of the source and receiver correction process are clearly visible on the displays: The subhorizontal layers appear to extend across the tomograms but to pinch out at the well bore locations. Single cross-hole tomograms such as these, as well as profiles constructed by concatenating several tomograms along a traverse, were used for estimation of hydrogeological parameters as will be described in sections 4 and 5. Although tomographic inversion tends to smear out lateral variations compared to vertical variations because of reduced angular coverage, the tomographic images at the Narrow Channel Focus Area suggest that the imaged units are less than $1 \mathrm{~m}$ thick and typically extend laterally for several meters. In sections 4,5 , and 6, we consider the estimates of geophysical attributes obtained from the inversion process as data available to us for use in our hydrogeological estimation procedures, and henceforth, we refer to these geophysical attribute estimates as our "geophysical data."

\subsection{Seismic Tomography}

Seismic methods are artificially generated high-frequency pulses of acoustic energy to probe the subsurface. For crosswell methods, piezoelectric devices or vibrators can generate these pulses. The pulse is produced at a point and propagates outward as a series of wave fronts. The wave front can be detected by a sensitive geophone or hydrophone and recorded on the surface. The seismic tomographic acquisition geometry is similar to that used by radar tomographic methods, which is illustrated in Figure 4b, except that seismic (rather than electromagnetic) signals travel from a transmitting to a receiving antenna. Tomographic seismic data can be processed in a manner similar to the method described above for radar tomographic data. Additional information about processing of seismic tomographic data is given by Peterson et al. [1985] and Rector [1995].

Eleven seismic tomographic profiles were collected at the same locations as the radar tomographic profiles shown in Figure $2 \mathrm{~b}$. These data were collected using a Geometrics Strataview seismic system, a Lawrence Berkeley National Laboratory piezoelectric source, and an ITI hydrophone sensor string. The central frequency of the pulse was $4000 \mathrm{~Hz}$, with a bandwidth from approximately 1000 to $7000 \mathrm{~Hz}$, and the source and geophone spacing in the well bores was $0.125 \mathrm{~m}$. The travel times were picked for all source-receiver pairs, and these data were inverted for $P$ wave slowness. The inversion was performed using the same straight-ray algebraic reconstruction technique [Peterson et al., 1985] and inversion procedure discussed in section 2.2. The reciprocals of the inverted slowness values were taken to produce two-dimensional images of seismic $P$ wave velocity. An example of contoured seismic velocity values obtained from this inversion process using data collected between wells B2 and T2 is shown in Plate 1b. Comparison of the seismic and radar attributes in Plate 1 suggests that given the acquisition parameters and geometry employed, the radar and seismic tomograms from the aerobic flow cell reveal similar spatial resolution and similar patterns of attribute variability.

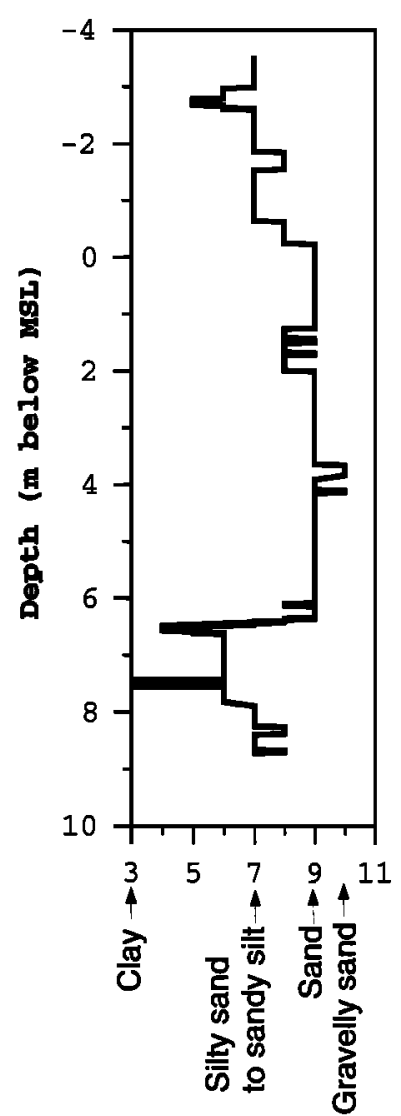

Figure 5. Example of CPT log NC4 collected within the aerobic flow cell (see Figure 2) and interpreted in terms of lithology indicator values using the empirical chart given by Robertson et al. [1986].

\subsection{Cone Penetrometer Data}

In a cone penetration (CPT) test a rod with a cone on the end is pushed into the ground at a constant rate, and measurements associated with the resistance to penetration of the cone into the subsurface are taken at discrete specified intervals. The most common measurement logs obtained from CPTs include the cone resistance (a measure of the total force acting on a cone divided by the projected area of the cone), the sleeve friction (the total force acting on the sleeve of the rod divided by the area of the sleeve), and the pore pressure. Friction ratio, expressed as a percentage, is the ratio of the sleeve friction to the cone resistance, both measured at the same depth. In general, sandy soils tend to produce high cone resistance and low friction ratio, whereas soft clay soils tend to produce low cone resistance and high friction ratio [Lunne et al., 1997]. CPT soil classification charts have been devised and used to enable estimation of soil type from CPT measurements such as cone resistance and friction ratio.

Seven cone penetrometer surveys were conducted throughout South Oyster Site. Each survey included measurements at $0.018 \mathrm{~m}$ intervals of sleeve friction, tip stress, and pore pressure. Using a soil classification chart from Robertson et al. [1986], the CPT data were converted into lithology indicator logs. Figure 5 is an example of the lithology indicator log constructed from a CPT log that is located closest to the tracer injection well within the aerobic flow cell (Figure 2b). This CPT lithology log suggests that there is a range of lithologies in 
the vicinity of this well, from organic material to gravelly sand. The chemical and bacterial tracer experiments were performed at the Narrow Channel Focus Area, however, in the saturated section only ( $\sim 0-6 \mathrm{~m}$ below $\mathrm{msl})$. In this zone the CPT data suggest that the lithology is predominantly sand, with minor amounts of gravelly sand and silty sand. Comparison of grain size distributions and lithology designations, obtained from the more traditional method of core sample analysis, with CPT measurements is underway. Preliminary analysis of these data suggests that the CPT measurements display less variability than is observed in core samples.

\subsection{Electromagnetic Flowmeter}

Electromagnetic borehole flowmeters were used within the aerobic flow cell to measure the flow distribution in pumped wells. This type of flowmeter is composed of an electromagnet and a pair of electrodes mounted at a right angle to the poles of the electromagnet. The electromagnet creates a magnetic field across the well flow passage. Since water is a conductor, water movement from the formation into the well and across this passage creates a voltage gradient according to Faraday's law of induction (the voltage induced across a conductor moving at right angles through a magnetic field is directly proportional to the velocity of the conductor). The microvoltage created by the moving water across the magnet is detected by the electrodes; this voltage is proportional to the average velocity of the water across the magnetic field and can be used to measure hydraulic conductivity [Molz and Young, 1993; Molz et al., 1994]

In the field a flowmeter log is recorded before pumping begins to detect any ambient flow in the well. After this recording, a small pump is placed in the test well and operated at a constant flow rate. After steady state behavior is obtained, flowmeter data are again collected at discrete intervals along the well bore. Because of the pumping, pore water enters the well screen, moves up the well, and is detected by the electromagnetic flowmeter. The difference between the pumped flowmeter profile and the ambient profile yields the net flow rate induced in each increment. Assuming that flow in the aquifer is horizontal, the amount of water entering the borehole within individual layers is proportional to the hydraulic conductivity in that layer, and a ratio of $K_{\text {unterval }} / K_{\text {average }}$ can be obtained. This ratio represents the horizontal component of hydraulic conductivity for each interval $K_{\text {interval }}$ relative to the average hydraulic conductivity of the logged interval, $K_{\text {average }}$ If $K_{\text {av }}$ erage information is available, for example, from a fully penetrating well test, the relative hydraulic conductivity ratios can be converted into hydraulic conductivity interval estimates $\hat{K}_{\mathrm{n}^{-}}$ terval using [Molz and Young, 1993]

$$
\hat{K}_{\text {interval }}=\left(\frac{K_{\text {interval }}}{K_{\text {average }}}\right)_{\text {flowmeter }}\left(K_{\text {average }}\right)_{\text {slug test }}
$$

Eleven flowmeter logs were collected by Quantum Engineering Corporation (QEC) for the Oyster project in the saturated zone of the aerobic flow cell and within the vicinity of the tracer injection well (Figure 2b). Slug test data, available in several of these wells, were used to provide $K_{\text {average }}$ values over the entire screen intervals. Comparison of all available slug test data in the aerobic flow cell suggested that the wells displayed a similar average value: The mean value of the slug test data for all wells was $5.53 \times 10^{-3} \mathrm{~cm} / \mathrm{s}$, with a variance of $1.56 \times$ $10^{-6} \mathrm{~cm} / \mathrm{s}$. The lowest $K_{\text {average }}$ value and average relative hy-



Figure 6. Example of flowmeter $\log \mathrm{S} 10$ interpreted in terms of hydraulic conductivity. Missing data are indicated where a casing joint existed. Eleven flowmeter logs were collected in the aerobic flow cell vicinity as shown in Figure $2 \mathrm{~b}$.

draulic conductivity values were obtained from well S10; this well is suspected to have been disturbed during drilling. Where slug test data were not available, the geometric mean of the slug test data over the entire flow cell was used. Hydraulic conductivity interval estimates were obtained from the flowmeter and slug test data as a function of depth in each well. Figure 6 is an example of flowmeter log S10 (see Figure 2b) interpreted in terms of hydraulic conductivity; this log is located approximately $8 \mathrm{~m}$ from the CPT lithology log shown in Figure 5. The values interpreted from this log are representative of silty to clean sands [Freeze and Cherry, 1979].

\section{Interpretation of Subregional and Local Stratigraphy}

As mentioned in section 1, the key criteria for choosing the two focus areas were that the two areas be located in the same or similar stratigraphic section but that they have different levels of hydrogeological heterogeneity and dissolved oxygen content. The surface GPR data, integrated with CPT logs, were used to assess the stratigraphic relationships of the South Oyster Site and to infer the level of heterogeneity. On the basis of the GPR data reflection strength, continuity, and character [Vail et al., 1977], reflectors were identified as bounding surfaces that separate wedge-shaped, seaward dipping and tapering, thin sequences (each with probable duration of less than 100,000 years). The sequences are $\sim 2-5 \mathrm{~m}$ thick with lateral extents of tens of meters in the geological dip direction. Their dips flatten seaward so that each sequence rests in the curve of its predecessor, and the whole forms a seaward offlapping succession, deposited during a period of oscillatory sea level fall [Mixon, 1985]. The updip end (blunt end) of each sequence 
terminates in a dune-beach deposit, representing a sea level highstand. The youngest, back barrier (lagoonal) deposits overlap the older two sequences, and wedge out at the foot of the Mappsburg Scarp.

Plate 2 shows an example of the interpreted subregional stratigraphy near the Narrow Channel Focus Area using two radar lines. The surface locations of the two reconnaissance GPR lines (lines 1000 and 1100) are annotated on Figure $1 \mathrm{~b}$ and Plate 3. Although these two lines are offset along geologic strike, together they offer a cross-sectional view of the subsurface stratigraphy from the Mappsburg Scarp to the aerobic flow cell. The two-way travel times of the radar reflections on these lines have been converted to approximate depths using an average velocity function obtained from nearby radar velocity tomograms. These radar profiles reveal the water table, as well as the series of reflectors bounding the successive sequences of the Wachapreague Formation. The red reflector marks the unconformable base of the Wachapreague Formation. The dip of this surface steepens as it approaches the surface toward the western (landward) margin of the study area and emerges as a subaerial surface, the Mappsburg Scarp. The shallower, younger, yellow reflector likewise rises steeply toward the west but does not rise to the subaerial surface. Instead, it terminates against the back barrier deposits of the red sequence. The location of the maximum dip of these reflectors, interpreted from the surface GPR data as the location of the buried shorefaces, are presented in Plate 3.

Lithology logs from analysis of CPT data were also used to interpret the regional stratigraphy. Cross sections were constructed using the CPT lithology logs throughout the Oyster Study Site. The CPT lithology logs were also superimposed on the radar cross sections (Plate 2). A comparison of the surface radar and CPT responses reveals lithological variations in the dip direction within the sedimentary sequences bounded by the annotated unconformities. To investigate bacterial transport under a range of conditions, a criterion of choosing the locations of the focus areas was that they have different groundwater chemistries. The CPT groundwater chemistry measurements (not presented in this study) were thus used to delineate zones having oxic and suboxic conditions.

The locations of the two focus areas were chosen on the basis of subregional stratigraphic information obtained from surface GPR and dissolved oxygen content measurements from the CPT data. Both the South Oyster and the Narrow Channel Focus Areas were chosen to be located within the same general stratigraphic interval and to the east of the interpreted buried shoreface associated with the yellow reflector. Additionally, the reflection character of the surface GPR data was used to assess the geologic complexity of the subsurface. The reflectors within the Narrow Channel Focus Area revealed simple, gently dipping and subhorizontal patterns interpreted to be associated with shallow marine deposits. The reflectors near the South Oyster Focus Area displayed more complex patterns, which, together with the CPT lithology logs, indicated the presence of a back barrier depositional environment. Although both focus areas are located within the same general stratigraphic package, the subsurface at the Narrow Channel Focus Area is geologically quite simple and has aerobic groundwater conditions, and the geology is more complex and the groundwater is suboxic at the South Oyster Focus Area. Plate 3 shows the locations of the focus areas and flow cells relative to the buried scarps to give an indication about the relative position of the study areas in the subregional stratigraphic section.

After choosing the locations of the focus areas a detailed grid of surface radar data, collected over the Narrow Channel Focus Area, was used to delineate the local stratigraphy there. Plate 4a shows an example of a detailed GPR line. On this line, colored lines show the location of mapped unconformities and other key horizons. These surfaces were mapped locally to produce structure contour maps of the subsurface; Plate $4 \mathrm{~b}$ is an example of depth structure contour maps on two surfaces constructed from the detailed GPR data. These maps reveal that the geologic structure characteristic of the aerobic flow cell is simple, with small undulations on otherwise gently dipping surfaces. Log permeability variations between these mapped surfaces were estimated using tomographic data, as described in section 4. Both the bounding surfaces, extracted from surface GPR data, and the hydraulic conductivity point value estimates, extracted from tomographic data as described in section 4 , are being used to constrain the numerical bacterial transport model of the aerobic flow cell [Scheibe et al., 1999].

\section{Hydraulic Conductivity Estimation}

Stochastic simulation methods were used to model flow and transport within the aerobic flow cell at the Narrow Channel Focus Area [Scheibe et al., 1999, 2001]. Stochastic modeling produces regular grids of hydraulic conductivity realizations given limited log permeability measurements and information about the spatial correlation function of log conductivity. Even at fairly homogeneous sites such as the Narrow Channel Focus Area, measurements of hydraulic properties are hindered by the difficulty of collecting representative and sufficient hydraulic property measurements using conventional sampling techniques, the spatial variability of hydraulic properties in natural geologic systems over a wide range of scales, and the dependence on the measurement support scale. In this section, we investigate the use of geophysical data as a supplement to hydrogeological measurements to provide detailed estimates of hydraulic conductivity. These estimates can be used to better constrain the numerical bacterial transport model and can be further analyzed to obtain spatial correlation information, as will be discussed in section 5 . As the ability to detect changes in physical and hydrological properties using geophysical data often varies with the method used, we employed both seismic and radar tomographic methods for this detailed characterization. We performed our hydraulic conductivity estimation in a stochastic framework using a Bayesian approach. This approach was developed by Rubin et al. [1992] and has been modified and expanded by Copty et al. [1993], Ezzedine et al. [1999], and Chen et al. [2001].

\subsection{Mathematical Statement of the Bayesian Approach}

The goal is to estimate hydraulic conductivity over the entire aquifer using all available information. Data that can be used in this estimation procedure include direct flowmeter hydraulic conductivity measurements, as well as sets of seismic or radar attributes available from tomographic data. The distribution of hydraulic conductivity at each location within the aquifer can be described by a probability distribution function (pdf). Log conductivity pdfs are assumed to be normally distributed and, as such, are completely described by their means and standard deviations.

The approach begins by estimating a log conductivity pdf at 


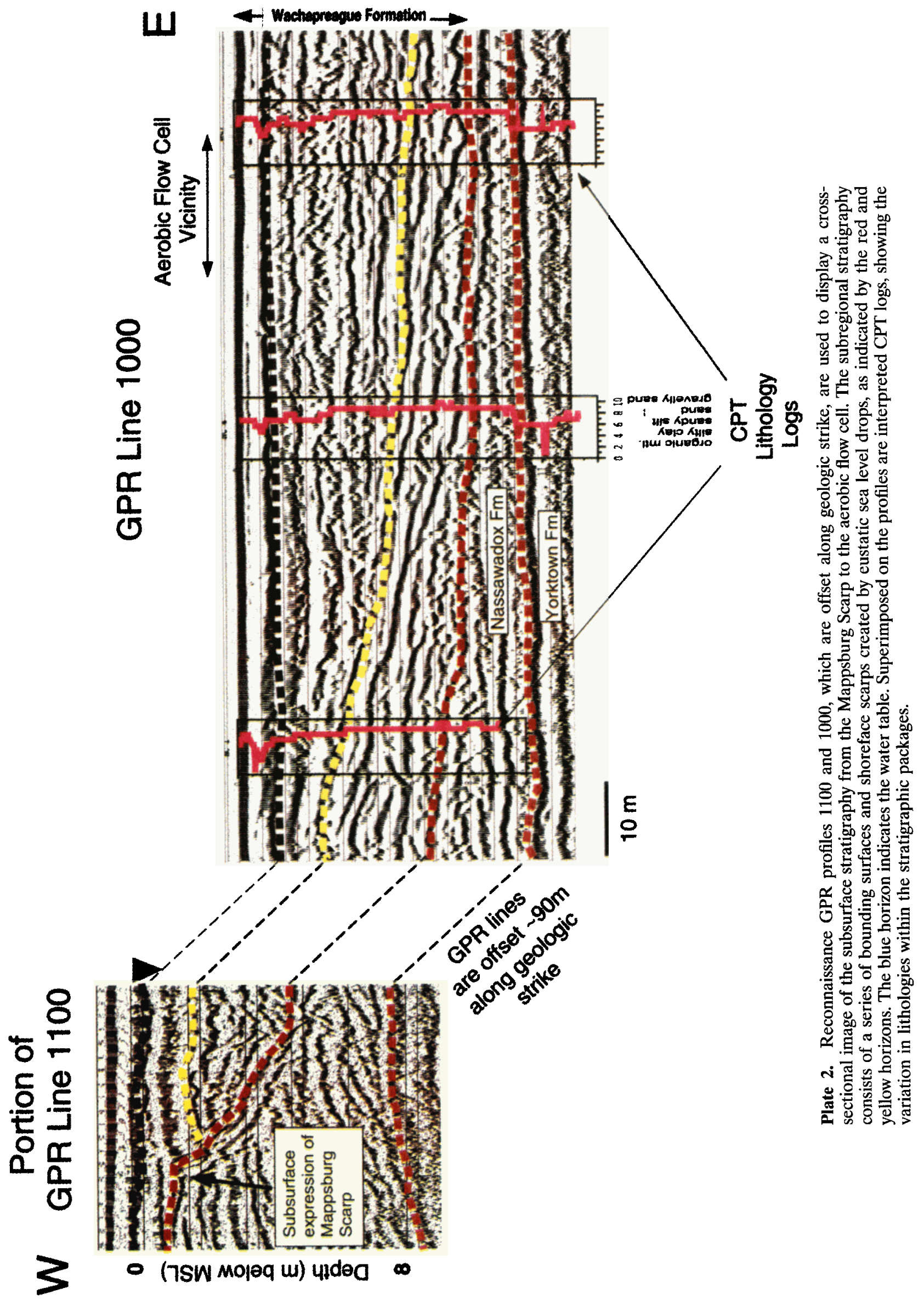




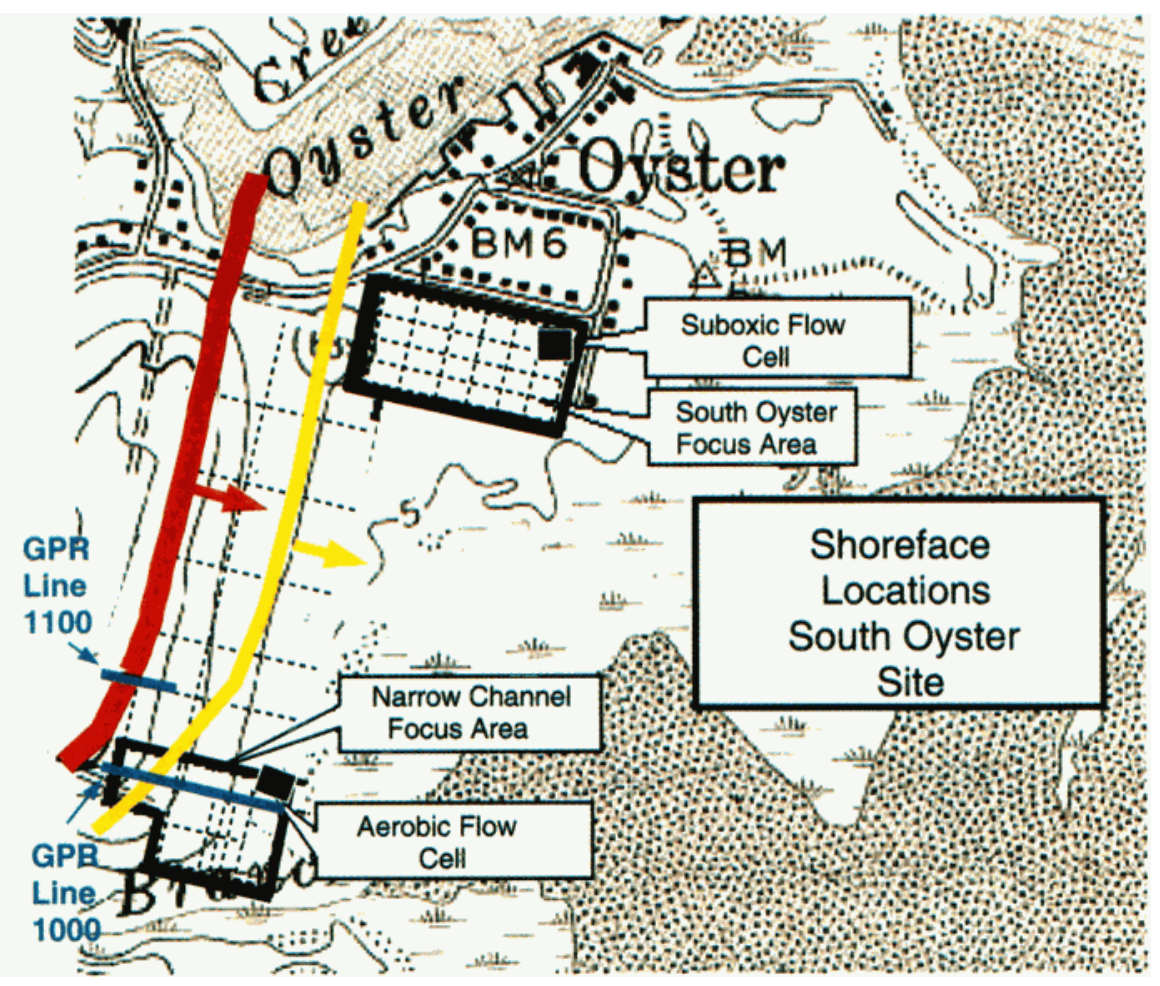

Plate 3. Interpretation of the major shorefaces at the South Oyster Site associated with the red and yellow unconformities that were delineated on the regional GPR lines as shown in Plate 2 . The regional stratigraphy and level of geological heterogeneity (interpreted from GPR data) and the groundwater chemistry (determined from CPT measurements) were used to choose the locations of the Narrow Channel and South Oyster Focus Areas.

each location between the boreholes where direct measurements exist. These estimates can be obtained, for example, using kriging techniques [Matheron, 1973] with hydraulic conductivity measurements from core data or flowmeters. These $\log$ conductivity estimates, obtained from the well bore data, are called "prior" pdfs. This distribution, obtained using only the direct measurements, represents the range of possible values at one location in space. Given the joint distribution between the geophysical attributes (such as seismic or radar velocities) and hydraulic conductivity, and the observed value of the geophysical measurement at that location, the prior distribution can be updated using Bayes' theorem [Ang and Tang, 1975]. The Bayesian approach allows for incorporation of complex and nonlinear petrophysical relationships between the geophysical and hydraulic parameters. The Bayesian concept is schematically illustrated in Figure 7. Figure 7a schematically shows an example of a prior log conductivity pdf at a single subsurface location. Figure $7 \mathrm{~b}$ illustrates an example of a joint distribution between the geophysical attribute under consideration and log conductivity, as well as the value of the geophysical measurement at the location corresponding to the prior log conductivity pdf. Using the joint distribution and the value of the geophysical attribute at the location where the prior is estimated (Figure 7b), the prior pdf (Figure 7a) can be updated using Bayes' theorem to obtain a posterior pdf. Figure 7c displays the posterior pdf obtained using the data shown in Figures 7a and $7 \mathrm{~b}$ and Bayes' theorem. The additional geophysical data and joint geophysical-hydrological information have rendered this posterior pdf considerably sharper than the prior pdf at the same location. Several synthetic studies by the aforementioned authors have shown that by including geophysical data into the estimation procedure using a Bayesian approach, the error and the standard deviation associated with the estimate can be significantly reduced.

\subsection{Hydraulic Conductivity Estimation at the Aerobic Flow Cell}

Application of the Bayesian methodology for estimating the $\log$ conductivity distribution at the Narrow Channel Focus Area is fully discussed by Chen et al. [2001] and is summarized in this section. Several data sets were used to produce threedimensional prior and posterior pdfs within the aerobic flow cell. Prior log conductivity fields were generated using a threedimensional kriging algorithm conditioned to the borehole flowmeter measurements. Relationships were developed using all well bore flowmeter logs and the geophysical attribute information obtained from the tomographic data in the vicinity of the well bore locations. As discussed in section 2.2, the geophysical values at the source and receiver well bore locations are often not reliable; for this reason, the relationships were developed using the geophysical attribute cell blocks located one column away from the wells rather than directly at the well bore locations. There are two assumptions inherent in the development of the petrophysical relationships in such a manner: (1) that the columns of geophysical attribute values located near the boreholes are sufficiently determined with sufficient resolution and (2) that the relationship is stationary. Given the high-quality nature of the tomograms obtained for this study and the small spatial extent of the aerobic flow cell 

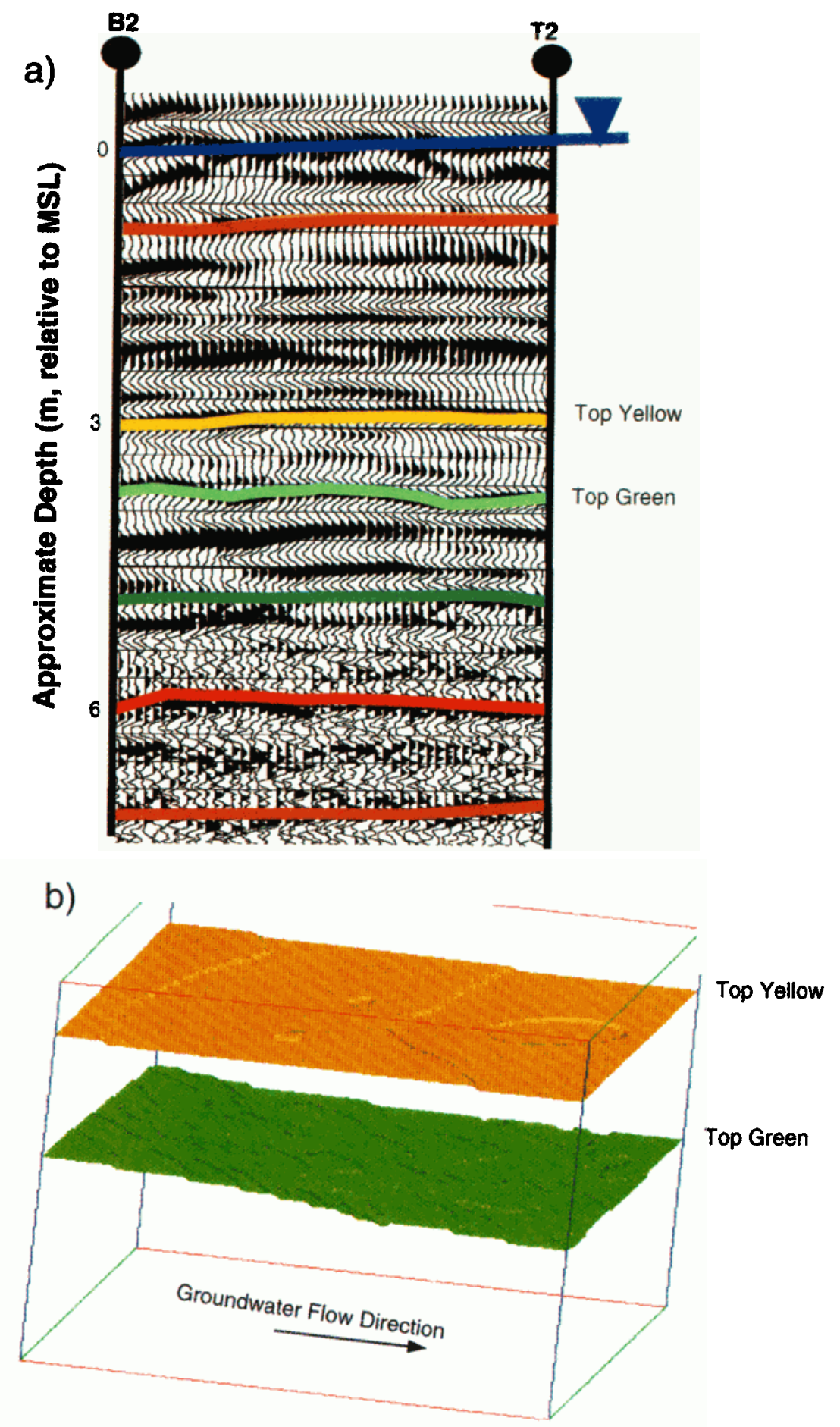

Plate 4. (a) Example of detailed GPR profile and interpreted horizons that were mapped within the aerobic flow cell at the Narrow Channel Focus Area. (b) Example of depth structure contour maps on two horizons obtained from detailed GPR lines. These maps were used within the numerical bacterial transport model as bounding surfaces.

where the tomograms were collected, we believe that these assumptions are reasonable for this study.

Figure 8 shows scatterplots between the tomographic attributes and $\log$ conductivity measurements, from which the likelihood functions were created. Figure 8 shows that the radar and seismic velocity measurements display a strong linear relationship and that these data correlate fairly well with $\log$ conductivity. These scatterplots also suggest a poor linear correlation between radar attenuation and $\log$ conductivity. Understanding the causal relationships between the geophysical attributes and log permeability for unconsolidated porous media is a current research topic of many investigators. For example, Marion [1990] and Knoll et al. [1995] found, using theoretical approaches and laboratory verification, that the 

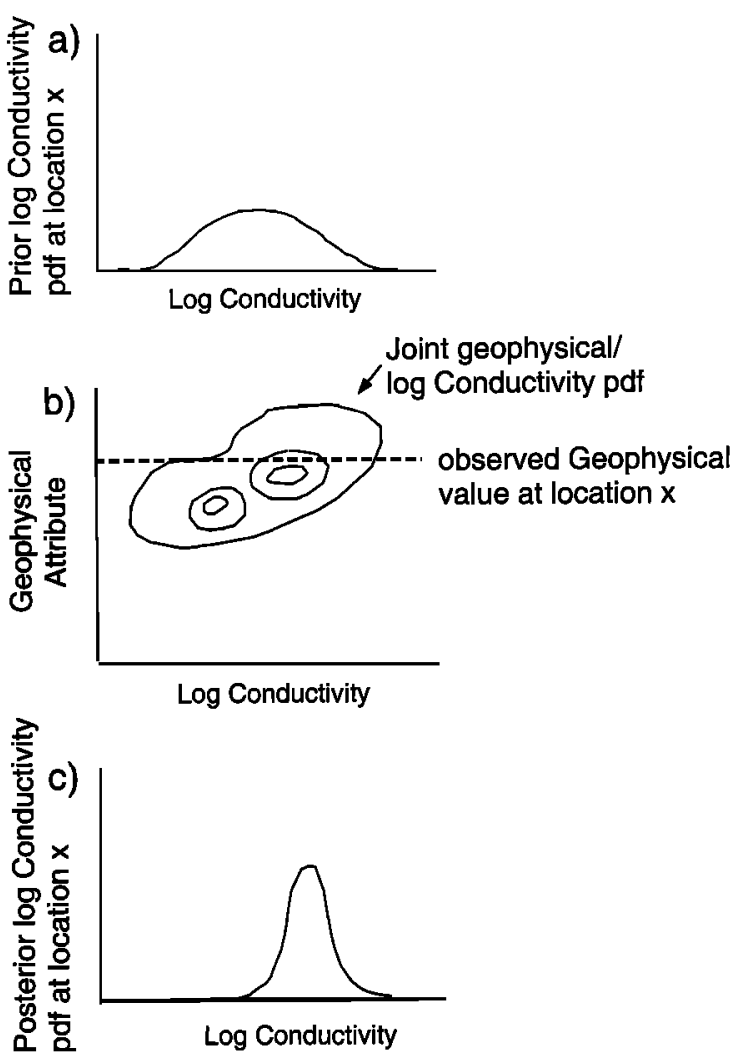

Figure 7. Schematic representation of Bayes' theorem using geophysical and hydrological data. (a) Example of prior log conductivity pdf. (b) Joint hydrological-geophysical distribution, and value of geophysical data at same location where prior exists. (c) Posterior log conductivity pdf updated using information shown in Figures $7 \mathrm{a}$ and $7 \mathrm{~b}$ and Bayes' theorem. This example shows how the mean can be altered and the standard deviation of the posterior pdf can be significantly reduced upon incorporation of geophysical data into the estimation procedure.

seismic and radar velocities in simple sand-clay systems were influenced by factors such as clay content and porosity. At the sand-gravel system present within the Narrow Channel Focus Area, however, the clay content is insignificant while gravel is a key component. We speculate that the geophysical attributes are linked to log conductivity predominantly through their sensitivity to variations in mean grain size, sorting, and porosity. Our laboratory investigations of Oyster sediment seismic attributes, physical parameters, and hydrological parameters [Hubbard et al., 1996] support this speculation. Although we are currently investigating the key controls on the geophysical attributes at the Oyster Site using colocated hydrogeological and geophysical data [Green et al., 2000], for this study the relationships between measured log conductivity values and geophysical attributes are modeled empirically.

Several measures of error were used to assess the utility of the geophysical data for hydraulic conductivity estimation. The prior log conductivity pdfs, created using flowmeter data, were updated for each location within the three-dimensional volume (Figure 2b) following Bayes' theorem. A comparison of the average standard deviations, computed from the prior and posterior pdfs at 10 "testing" well bore locations within the aerobic flow cell, was used to assess the model error. A crossvalidation exercise using the Bayesian log conductivity esti- mates at the 10 testing wells was used to assess the true error associated with the prior and posterior estimates [Chen et al., 2001]. The true errors were calculated as the space averages along the wells of the absolute differences between actual and estimated values. Figure 9 displays the averages of the model and true error calculated using 10 wells in the aerobic flow cell [Chen et al., 2001]. The results of these exercises suggested that the model error is much larger than the actual error when only the well bore flowmeter measurements are used. Incorporation of the radar tomography information into the Bayesian scheme, however, decreased the model error substantially, and as well decreased the true error. Because of the strong linear relationship between the seismic and radar velocities, as well as the poor correlation between radar attenuation and log conductivity, inclusion of seismic velocity and radar attenuation into the estimation procedure did not substantially improve the true error compared to those estimates obtained using only radar tomographic velocity information but did improve the model error. However, in more complicated systems with varying lithologies, for example, at the South Oyster Focus Area, this may not be the case, and the multiple, colocated data fields may offer information necessary to resolve estimation ambiguities. The error estimation exercises suggested that although the log conductivity variation at the aerobic flow cell was small (and hence the geophysical data varied only over a small range) and the amount of well bore data available for direct characterization was greater than what is typically available at a field site, the geophysical data still improved the estimates of hydraulic conductivity. The improvement was most significant where prior information was limited, such as at distances greater than a few meters from the well bores.

Within the aerobic flow cell, only the radar tomographic data were used within the Bayesian routine to update the prior pdf estimates obtained from flowmeter data. Plate 5 shows an example of the means of the hydraulic conductivity posterior pdfs along a stratigraphic dip profile (between tracer injection well B2 and well M3) and along a stratigraphic strike profile (between wells T1 and S12), obtained using tomographic radar velocity and direct flowmeter data in the Bayesian routine. Superimposed on this fence diagram is a flowmeter log at well S9, plotted using the same hydraulic conductivity scale (as annotated beneath the $\log$ ) as the tomographically obtained estimates. This fence diagram shows that the imaged units are horizontal to subhorizontal, typically less than a meter thick, extend in both the stratigraphic dip and strike directions for distances of several meters, and have a hydraulic conductivity range of only $\sim 1$ order of magnitude.

A comparison between prior and posterior hydraulic conductivity pdf means along the injection centerline (between tracer injection well $B 2$ and well $M 3$, see Figure $2 b$ ) is shown in Plates 6a and 6b. As discussed above, the prior pdfs (Plate 6a) were created by kriging densely sampled flowmeter data over the three-dimensional study volume, and the posterior pdfs (Plate 6b) were created using the prior information together with petrophysical relationships developed for the site and all radar tomographic velocity measurements within the Bayesian procedure. Because of imposing a three-dimensional grid upon the study volume and the orientation of the twodimensional tomography transects within this volume, some of the well bore locations do not coincide exactly with the pixels that define the tomography traverses. As a result, when comparing prior and posterior estimates whose values were conditioned upon the well bore measurements, estimates at well 



\section{Log Conductivity $(\mathrm{m} / \mathrm{hr})$}

Radar Velocity (cm/ns)

Radar Attenuation (1/m)

Figure 8. Scatterplots of the geophysical attributes versus hydraulic conductivity obtained from colocated flowmeter and tomography data. Likelihood relations were empirically modeled from these data and used in the Bayesian log conductivity estimation procedure.

locations whose pixels coincide exactly with a pixel along the tomographic traverse will have zero variance and no change in the mean value, while estimates associated with wells that fall slightly off of the transect may be slightly updated in the Bayesian estimation procedure. For example, along transect B2-M3 (shown in Plates 6a and 6b) the true locations of wells B2 and M3 are located digitally along the transect, while the other wells (wells S10, S14, and T2) are located slightly off of the tomographic traverse. As a result, the prior and posterior values at wells B2 and M3 are not altered, but there are slight differences in the values at well S10, and even slighter differences at wells S14 and T2.

Comparison of the prior and posterior pdf means shows, in general, that near the annotated borehole locations where flowmeter data exist, the estimates are similar. However, in the areas between the well bores that are a meter or more from the wellbore flowmeter data control, inclusion of the geophysical data into the estimation procedure yields different log conductivity estimates. For example, the high-conductivity zone between wells T2 and M3 at a depth of 4-5 m and the lowconductivity zone between the same two wells at a depth of $\sim 3$ $\mathrm{m}$ are much more extensive and well defined on the posterior image (Plate 6b) than on the prior image (Plate 6a). The comparison also illustrates how incorporation of flowmeter data with the tomographic data helps to improve the overall appearance of the transect. For example, at the well bore locations, where application of a source/receiver correction applied during the inversion caused the imaged layers to appear to be pinched out on the original tomogram image (as shown in Plate 1 and discussed in section 2.2), the layers now extend across the entire tomogram. Additionally, vertical features, such as the low-conductivity disturbed zone thought to be associated with the drilling of well S10, cannot be resolved by tomographic rays passing at horizontal or subhorizontal angles through the feature, but are apparent upon integration of the flowmeter and tomographic data. The disturbance associated with well $\mathrm{S} 10$ is not suspected to be a flowmeter measurement artifact, as breakthrough data suggested that this low-conductivity feature influenced both the travel path of the bromide and bacterial tracers [Johnson et al., 2001]. Analysis of the Bayesian estimation results illustrates that the variations in $\log$ conductivity, even within fairly homogeneous environments such as exist at the aerobic flow cell, can be difficult to estimate given only a single type of characterization data. As these 


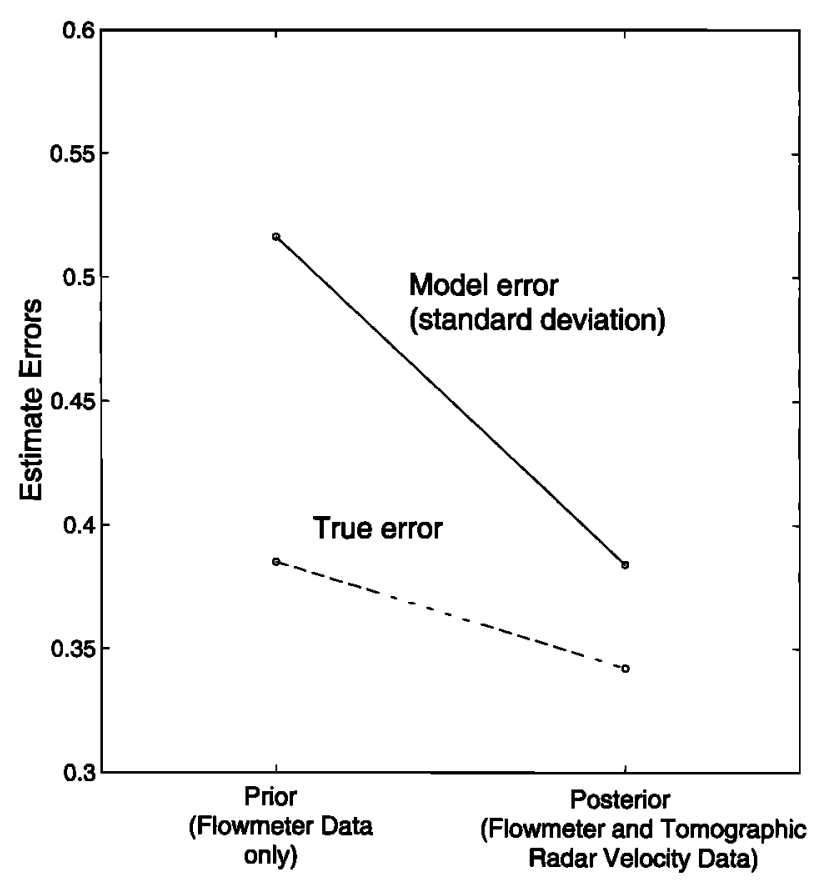

Figure 9. Comparison of average true errors, which were computed during a cross-validation exercise using 10 "testing" wells within the aerobic flow cell, and the average model errors, which were determined by comparing the average standard deviation of the prior pdfs with those of the posterior pdfs at the same wells. This figure shows how both true and model errors decrease upon inclusion of radar tomographic data into the estimation procedure. Computations are originally from Chen et al. [2001], with units of hydraulic conductivity in $\mathrm{m} / \mathrm{h}$.

variabilities can be crucial for predicting flow and transport through the system, the importance of integrating complementary data sets, such as well bore and tomographic data, during the characterization procedure is highlighted.

The posterior hydraulic conductivity estimates obtained from the tomographic data were used to assist in development of the bacterial injection field experiment. For example, for the first bacterial injection experiment at the South Oyster Site it was desired that the bacteria be injected into a permeable zone to improve the chances of long-distance bacterial transport [Johnson et al., 2001]. The image shown in Plate $6 \mathrm{~b}$ was used to choose a high-hydraulic-conductivity unit as the key injection zone for the chemical and bacterial tracers. This lower injection zone is located at a depth of approximately $4.8 \mathrm{~m}$ below $\mathrm{msl}$ at the injector well B2 and overlies a low-hydraulicconductivity zone. This image was also used to assist in the design of the multilevel sampler placement [Johnson et al., 2001; Scheibe et al., 2001].

In addition to using these estimates to assist in the design of the field experiment, the hydraulic conductivity information obtained from tomographic data has been used to constrain the numerical bacterial transport model [Scheibe et al., 1999, 2001] and to assist in the interpretation of the bacterial transport data collected at the Narrow Channel Focus Area. Improved estimation of log conductivity can reduce the uncertainty typically associated with that variable when interpreting field-scale bacterial breakthrough data and thus can ultimately help in a better understanding of bacterial transport. The hydraulic conductivity estimates obtained from tomographic data at the aerobic flow cell were used by Johnson et al. [2001] in the interpretation of the bacterial breakthrough data collected there during the transport experiment. Using these data, Johnson et al. [2001] found that the timing of breakthrough of the adhesion-deficient bacterial strain at this site was controlled by the hydrogeological heterogeneity as opposed to variation in sediment surface or aqueous chemical properties. Although a topic of ongoing research, these studies suggest that the information provided by the tomographic data at the Narrow Channel Focus Area were of an appropriate support scale and resolution to assist with the interpretation of the field-scale bacterial transport data at this site.

\subsection{Comparison of Tomographic Radar, Surface Radar, and Borehole Information}

Plate 7 compares the information and resolution offered from radar tomography, radar surface, and flowmeter characterization methods. Plate 7a illustrates the means of the estimated log conductivity pdfs obtained from tomographic data, as described in section 4.2 , between wells $\mathrm{B} 2$ and $\mathrm{T} 2$ along the injection centerline. Plate $7 \mathrm{~b}$ displays the corresponding 100 $\mathrm{MHz}$ detailed surface GPR line, similar to those detailed lines discussed in section 2.1, along the injection centerline between wells M1 and M3 and including the traverse between B2 and T2 (see Figure 2b). Superimposed on this line are the key horizons mapped to provide structure contour maps, as shown in Plate 4b, the interpreted water table, and hydraulic conductivity measurements from flowmeter data collected as described in section 2.5. This image shows that these methods, given our acquisition parameters and geometry at this site, yield information with similar spatial resolution. The surface data were most useful for delineating boundaries between units having different properties, while the tomographic data provided high-resolution estimates of within-unit variations in $\log$ conductivity; both types of information were used as input to the numerical flow model [Scheibe et al., 1999].

\section{Structural Correlation Estimation}

For a typical detailed characterization project involving tomographic data, geophysical profiles only traverse a small portion of the aquifer under consideration. Within the aerobic flow cell, a highly sampled study site, we estimate that the tomographic data sampled approximately $5 \%$ of the transport experiment study volume. Thus, even when tomographic data are available for log conductivity estimation as described in section 4 , data are typically insufficient to assign a hydraulic conductivity value to each grid block within a threedimensional numerical bacterial transport model. Hydraulic conductivity values for the remaining portions of the aerobic flow cell study volume in this and other studies are often obtained using stochastic simulation routines, which require information about the hydraulic conductivity structure as input.

Well bore data are sometimes useful for obtaining information about the correlation structure in the vertical direction, but the measurements are rarely dense enough horizontally to provide sufficient information about the horizontal correlation structure. In this section, we investigate the use of tomographic data as a supplement to hydrogeological measurements to estimate structural correlation parameters. We perform the structural inference procedure in the spectral domain. This facilitates integration between data with different support scales and spatial sampling windows because it represents the 
spatial phenomena as being composed of variations characterized by scales of different lengths. A complete presentation of the spectral domain correlation estimation procedure, discussion of the benefits and limitations of the method, and accompanying synthetic case studies are fully described by Hubbard et al. [1999]. For completeness the approach is summarized below.

We model the log conductivities at the Narrow Channel Focus Area as stochastic processes that can be characterized by their spatial covariance structures. Examples of spatial covariance structures and parameters for various geological conditions were presented by Rubin et al. [1998]. An example of a two-dimensional log conductivity exponential covariance structure is given by

$$
C_{Y}(\mathbf{r})=\sigma_{Y}^{2} \exp \left[-\left(\frac{r_{1}^{2}}{I_{1}}+\frac{r_{2}^{2}}{I_{2}}\right)^{1 / 2}\right],
$$

where $\sigma_{Y}^{2}$ is the variance of the $\log$ conductivity $Y, r_{1}$ and $r_{2}$ are the log conductivity measurement separation distances, $I_{1}$ and $I_{2}$ are the corresponding integral scales, and subscripts 1 and 2 refer to the directions perpendicular and parallel to bedding, respectively. The variance indicates dispersion of the properties around the mean value of the distribution, and the integral scale is a measure of the separation distance at which the measurements become weakly correlated. Anisotropy $\alpha$ of the hydrogeological properties is a function of the geometric organization that commonly exists in geologic strata. In our twodimensional studies the anisotropy ratio is defined as $I_{2} / I_{1}$. This spectral domain procedure involves the estimation of the variance, integral scales, and anisotropy ratio of the hydraulic properties using hydrological and tomographic data along twodimensional traverses coincident with the tomographic profiles.

\subsection{Spectral Representation of Data}

With this spectral technique we investigate the spatial correlation information available from flowmeter measurements and from estimates of log conductivity obtained using highresolution two-dimensional tomographic data. The spatial correlation parameters associated with a one-dimensional, uniformly spaced measurement series can be investigated using the amplitudes obtained from Fourier transformation of the data, $a\left(k_{m}\right)$, where $k_{m}$ denotes the wave number in the Cartesian direction $m=1,2$ [Bracewell, 1965; Gardner, 1988]. In this study, we work with uniformly spaced samples and express the energy spectrum obtained from these amplitudes as a spectral density function $S\left(k_{m}\right)$ :

$$
S_{\eta}\left(k_{m}\right)=\left\langle a_{\eta}\left(k_{m}\right) a_{\eta}\left(k_{m}\right)^{*}\right\rangle,
$$

where $\eta=Y$ or $G$ refers to $\log$ conductivity or geophysical measured data, respectively, $m$ denotes the spatial direction, the asterisk denotes the complex conjugate, and the angle brackets denote the expected value. No summation over repeated indices is implied in (3) or in subsequent expressions. Spatial correlation functions such as that given by (3) can be expressed as spectral density functions using Fourier transformations as discussed by Dagan [1989] and Gelhar [1993].

If more than one measurement series is available in the same direction, individual spectra can be averaged to obtain an average spectral density curve. For example, if several core sections of the same length and sampling interval are available from several well bores, the average spectral density function for $\log$ permeability in the vertical direction can be obtained by averaging the well bore data spectral density functions. Similarly, space-averaged vertical and horizontal spectral density functions can be calculated from two-dimensional data, such as from a geophysical tomogram, by calculating the average onedimensional spectral density function along the vertical direction and then repeating the procedure along the horizontal direction. The space-averaged spectral density function can be calculated over $d$ individual data measurement series (such as core sections and tomographic rows or columns) using

$$
\bar{S}_{\eta}\left(k_{m}\right)=\frac{1}{d} \sum_{j=1}^{d} S_{\eta}^{(j)}\left(k_{m}\right),
$$

where the superscript $j$ denotes row, column, or core section over which the averaging is taking place and the horizontal bar denotes space averaging.

Spectral density functions are calculated from measured data as a function of wave number, or spatial frequency. For all data types the low-wave-number cutoff for the spectral density function is proportional to the inverse of the sampled domain size, $1 / D$ (in units of the reciprocal of the distance). For data sampled with a spatial interval of $L$ (in units of samples per distance) the spatial Nyquist frequency $(L=1 / 2)$ dictates the high-wave-number cutoff, or the highest wave number that can be detected using that sampling interval. Thus, to be of any value, the frequencies associated with the hydrological heterogeneity must be lower than the measured data Nyquist frequency but higher than the frequencies associated with the low-wave-number cutoff in order to be detected by that particular set of measurements. The low-wave-number cutoff $k_{\text {min }}$ is expressed as $2 \pi / D$, and the high-Nyquist-wave-number cutoff $k_{N}$ is expressed as $2 \pi L_{N}$ [Ababou and Gelhar, 1990].

\subsection{Estimation Procedure}

The integral scale and variance parameters can be estimated from the spectral density curve by first assuming that a particular structural model is applicable to the study site under consideration. The correlation model may be obtained, for example, from previous investigations within the aquifer under investigation or within another geologically similar aquifer. Transformation of the chosen correlation model into the spectral domain and fitting of the spectral density curve with the transformed correlation model representation enables estimation of the correlation parameters. For example, the Fourier transformation of a one-dimensional, exponential covariance structure yields the log permeability exponential spectral density function

$$
S_{Y}\left(k_{m}\right)=\frac{\sigma_{Y}^{2} I_{m}}{\pi\left(1+k_{m}^{2} I_{m}^{2}\right)},
$$

where $\sigma_{Y}^{2}$ is the $\log$ permeability variance and $I_{m}$ is the integral scale in the direction $m=1,2$ [Gelhar, 1993]. To implement this estimation approach, the experimental spectral density function, obtained from the measured data using (3) or (4), can be equated to the right-hand side of (5) and fit to estimate $I_{m}$ and $\sigma_{Y}^{2}$ using a variety of statistical fitting procedures. To improve the stability of the fit, the variance in (5) can be estimated using a discretized representation of the expression given by Gelhar [1993] prior to fitting for the integral scale:

$$
\sigma_{Y}^{2}=\Delta k_{m} \sum_{k_{m}=-\infty}^{k_{m}=+\infty} S_{Y}\left(k_{m}\right) .
$$




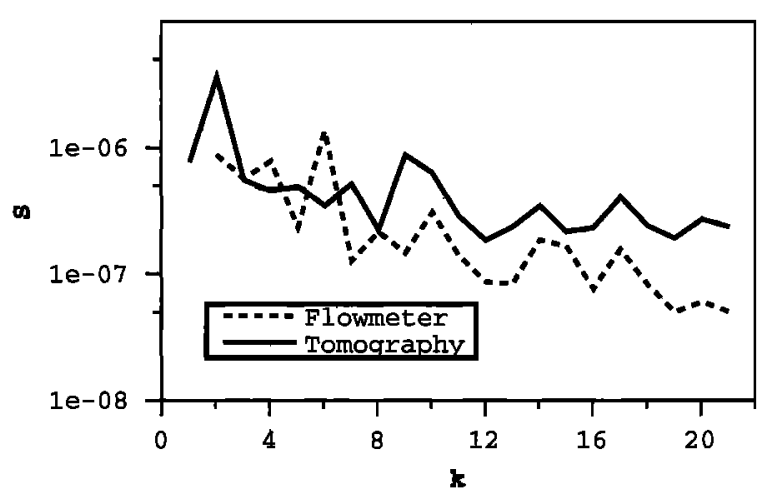

Figure 10. Spectral density curves in the vertical direction obtained from direct flowmeter data and from tomographic estimates of hydraulic conductivity. Read $1 \mathrm{e}-06$ as $1 \times 10^{-6}$.

In summary, our procedure to estimate the structural correlation parameters consists of the following three steps: (1) Obtain log permeability measurements or estimates from hydrological or tomographic data. (2) Transfer this information into Fourier space and calculate the one-dimensional experimental spectral density functions. If two-dimensional data are available, calculate the average spectral density function in each direction. (3) Fit the experimental spectral density curve to solve for the integral scale and variance using (5) if the correlation structure is assumed to be exponential, If the correlation structure is assumed to be another type of model, fit the experimental density curve to the Fourier representation of that model to solve for the integral scale and variance. Alternatively, the variance can be calculated using (6) and substituted into (5) prior to fitting for the integral scale.

\subsection{Estimates of Spatial Correlation Parameters Using Tomographic Data}

In this section, we investigate the spatial correlation parameters in the aerobic flow cell area using both direct flowmeter measurements (as described in section 2.5) and estimates of hydraulic conductivity obtained using tomographic data (obtained as described in section 4). The measured log conductivity values from the flowmeter logs were transformed into the wave number domain using fast Fourier transforms. An average vertical spectral density curve was obtained from the flowmeter data using (4); this spectral density curve is shown in Figure 10. Vertical spectral density information was then calculated using the hydraulic conductivity information in the dip direction obtained from tomographic data (Plate 6b). If only the means of the posterior conductivity pdfs are used to estimate spatial correlation information, the high-frequency variations that may be present in the actual fields would not be detectable. To ensure that all frequency components of the

Table 2. Log Conductivity Variance and Vertical Integral Scale Estimated Using Flowmeter and Tomographic Data Within the Aerobic Flow Cell

\begin{tabular}{lccc}
\hline $\begin{array}{c}\text { Data Used to Construct } \\
\text { Spectral Density } \\
\quad \text { Function }\end{array}$ & $1 / L, \mathrm{~cm} / \mathrm{sample}$ & $\hat{\sigma}_{\ln K}^{2}, \mathrm{~cm} / \mathrm{s}$ & $\check{I}_{1}, \mathrm{~cm}$ \\
\hline Flowmeter data & 15 & 0.33 & 20 \\
Radar tomography data & 15 & 0.34 & 28 \\
\hline
\end{tabular}

model are represented during spatial correlation estimation, we calculated the differences between the log permeability values, obtained from flowmeter measurements, and nearby estimated hydraulic conductivity means, obtained from tomographic data. These error residuals were modeled, and random error with the modeled distribution was added to the conductivity mean estimates. We then calculated the average vertical spectral density function from the two resulting data sets that correspond to the tomographic profiles using (4); this tomographically obtained log conductivity spectrum is also shown in Figure 10. Figure 10 illustrates that the average vertical spectral density curves obtained from flowmeter and tomographic data are similar, especially at the low-wave-number end of the spectrum. The tomographic data had a longer sampling window and thus were able to capture more low-frequency information than the flowmeter data. As the sampling intervals were the same for both the flowmeter and interpreted tomograms, the high-frequency cutoff is the same.

The spectral density curves shown in Figure 10 were analyzed following the approach presented in section 5.2. Vertical integral scales were calculated from both flowmeter and average tomographic spectral curves by assuming an exponential structural covariance model and using (5) with the variance calculated using (6); to fit our measured data to the theoretical density expression, we used a Gauss-Newton nonlinear least squares procedure [Ratkowsky, 1983]. The results of the spatial correlation parameter estimations in the vertical direction are shown in Table 2 , in the rows "Flowmeter Data" and "Tomography Data."

Table 2 shows that analysis of both the tomographic and flowmeter spectral data yield vertical integral scale estimates of $\sim 20-30 \mathrm{~cm}$. The larger integral scale values obtained from the tomography data may be due in part to low-frequency information that the tomography data were able to sample compared to the flowmeter data, which did not traverse as long of a sampling window. Even with highly sampled borehole data available at the Narrow Channel Focus Area, it was difficult to extract reliable information about horizontal spatial correlation parameters using only flowmeter data. Although tomographic inversion can result in increased smoothing in the horizontal direction relative to the lateral direction (as discussed in section 2.2), we still found that these soft data provided reasonable information about lateral variability. A similar analysis of both tomography profiles shown in Plate 5 in the horizontal direction suggested that the horizontal integral scale is $\sim 1.5 \mathrm{~m}$, which yields an anisotropy estimate of approximately 5 . This analysis suggests that the tomography data can be integrated with borehole data to provide denser estimates of hydraulic conductivity, as well as more complete information about conductivity spatial correlation structure, especially in the horizontal direction.

\section{Estimation of Bromide Plume Spatial Moments}

In this section, we compare the information obtained from geophysical data with conservative chemical breakthrough data. In addition to the validation tests performed by Chen et al. [2001] this exercise helps to assess the merit of tomographic data for providing hydrogeological information. To do this, we first visually and qualitatively compare the spatial patterns of hydraulic conductivity provided by geophysical data to bromide breakthrough data. In this manner, we assess whether the 




Plate 5. Estimated means of the log conductivity pdfs obtained from tomographic data located along the injection centerline (in the geologic dip direction) from injection well B2 to well M3 and the geologic strike direction from wells T1 to S12. Superimposed on the fence diagram are log conductivity measurements obtained from a flowmeter at well bore S9. Note that the tomography profile B2-M3 is plotted in a reverse direction (compared to images shown in Plates 1,6,7, and 8) in order to display the longer section of the strike tomographic profile T1-S12.

plume follows the paths that would be expected given the hydraulic conductivity estimates. Using a more quantitative approach, we subsequently estimate plume longitudinal spatial moments using geophysical information. These estimated moments are then compared with moments obtained from visual inspection of the bromide breakthrough data. For this cursory assessment we compare our tomographic-obtained estimates with observations of bromide breakthrough measured in a time-lapse fashion during the bromide injection experiment conducted in 1999 within the aerobic flow cell shown in Figure $2 \mathrm{~b}$. We perform our comparison along the expected injectate centerline, from the tracer injection well (B2) to $7 \mathrm{~m}$ downgradient from that well between depths of approximately 4.4 and $6.0 \mathrm{~m}$ below msl. Plate $8 \mathrm{a}$ shows the portion of the estimated hydraulic conductivity pdf means, obtained from tomographic data as described in section 4, along this traverse; this area represents a lower portion of the hydraulic conductivity pdf mean values estimated from tomographic data and shown in Plate $6 \mathrm{~b}$. The dotted lines indicate locations of the multilevel sampler ports that are located at $27.9 \mathrm{~cm}$ intervals within the sampling wells.

The bromide injection experiment consisted of injecting a 12 hour bromide pulse with an initial concentration of $100 \mathrm{ppm}$ into an isolated injection zone centered at ports 8 and 9 within well B2. The overall injection rate of $5 \mathrm{~L} / \mathrm{min}$ into well B2 included injection of approximately $1 \mathrm{~L} / \mathrm{min}$ of bromide within the isolated injection zone and injection of $\sim 4 \mathrm{~L} / \mathrm{min}$ of water above the isolated zone to create forced gradient conditions as described by Scheibe et al. [2001]. Bromide concentrations were sampled at all downgradient multilevel samplers as a function of time. Plates $8 \mathrm{~b}, 8 \mathrm{c}$, and $8 \mathrm{~d}$ show the bromide concentrations relative to the initial concentration at 12,48 , 

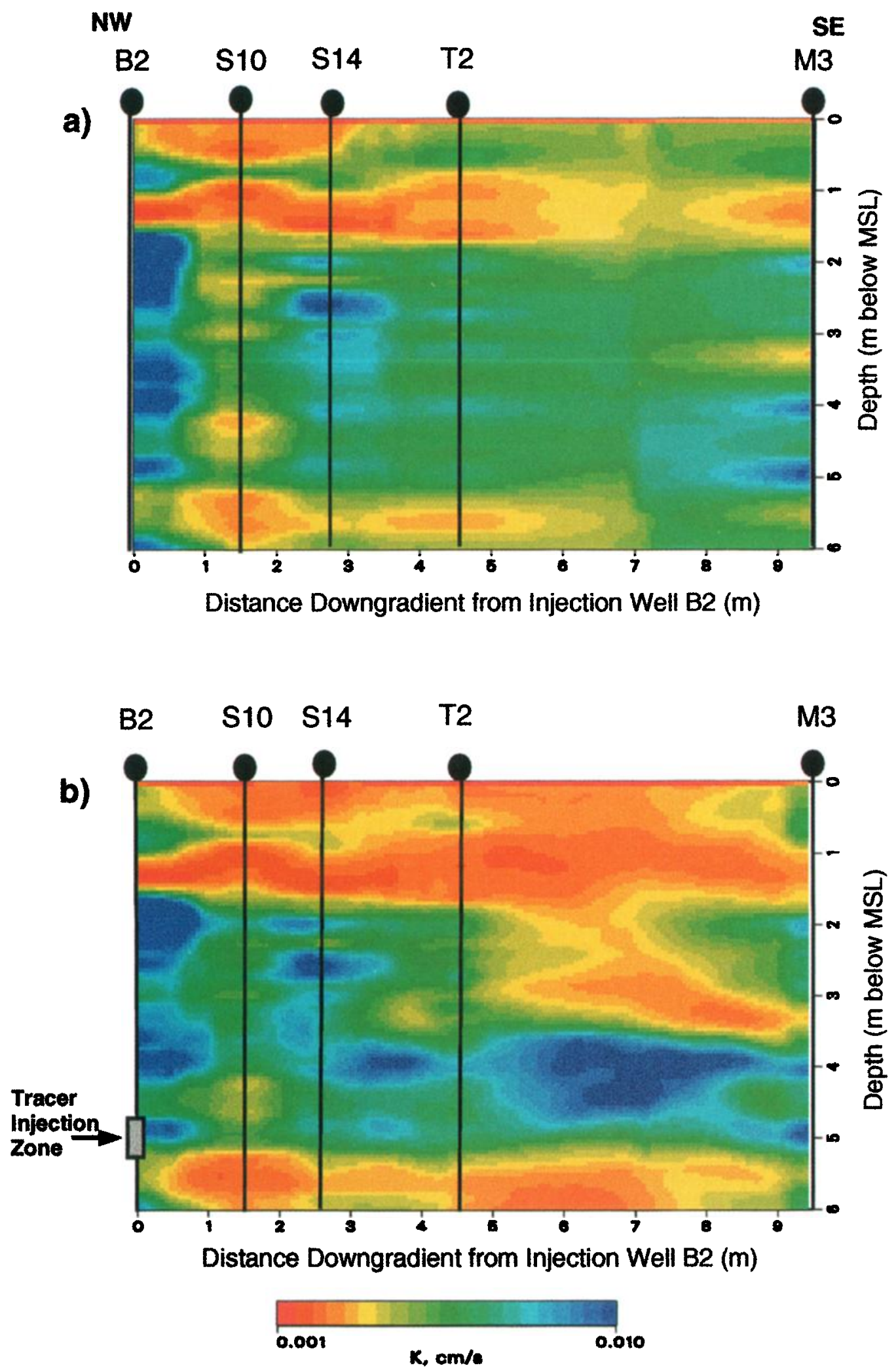

Plate 6. Comparison of the means of the (a) prior pdf (constructed from flowmeter data) and (b) posterior pdfs (constructed from flowmeter and tomography data) along the injection centerline. This image illustrates that flowmeter data alone were unable to capture the variability in hydraulic conductivity at distances of over a few meters from the direct well bore measurements at the aerobic flow cell. 







\section{Estimated Hydraulic Conductivity from Tomography Data}



Plate 8. Comparison of the (a) log conductivity values estimated using tomographic data at the lower injection zone (a portion of the image shown in Plate $6 \mathrm{~b}$ ) with bromide relative concentration at (b) 12 hours after bromide injection, (c) 48 hours after injection, and (d) 200 hours after injection. The black dots indicate the locations of sampling ports on the multilevel samplers. Visual examination suggests that the plume travels quickly along the high-hydraulic-conductivity zone(s) interpreted using the tomographic data and, after long times, resides in the low-conductivity zone. A more quantitative comparison of the plume length scales observed in these images and plume spatial moments estimated using tomographic information (Table 3) suggests the utility of tomographic methods for providing information necessary for flow and transport modeling. 
Table 3. Estimated Velocity and Plume Length Scales at 12, 48, and 200 Hours Obtained From Geophysical Data To Be Compared With Parameters Inferred From Inspection of Plates 8b, 8c, and 8d, Respectively ${ }^{a}$

\begin{tabular}{|c|c|c|c|c|c|}
\hline $\begin{array}{c}\text { Mean Flow Velocity } \\
\text { Estimated Using } \\
\text { Tomographic Data } \\
U=K_{G} J / n, \mathrm{~m} / \mathrm{d} \\
\end{array}$ & $\begin{array}{c}\text { Longitudinal Dispersion } \\
\text { Coefficient Calculated } \\
\text { Using } D_{x}= \\
\sigma_{Y}^{2} I_{Y, \text { horizontal }} U, \mathrm{~m}^{2} / \mathrm{d}\end{array}$ & Observation Time $t$ & $\begin{array}{l}\text { Measured Mean Flow } \\
\text { Velocity } U=x,{ }^{b} \mathrm{~m} / \mathrm{d}\end{array}$ & $\begin{array}{l}\text { Standard Deviation } \\
\text { Calculated Using } \\
\sigma_{x}=\sqrt{2 D_{x} t}, \mathrm{~m}\end{array}$ & $\begin{array}{c}\text { Longitudinal Plume } \\
\text { Length Estimated } \\
\text { Using } 6 \sigma_{x}, \mathrm{~m} \\
\end{array}$ \\
\hline $\begin{array}{l}0.7 \\
0.7 \\
0.7\end{array}$ & $\begin{array}{l}0.323 \\
0.323 \\
0.323\end{array}$ & $\begin{array}{l}12 \text { hours }(0.5 \text { days }) \\
48 \text { hours }(2 \text { days }) \\
200 \text { hours }(8.33 \text { days })\end{array}$ & $\begin{array}{l}1.2 \\
1.25 \\
0.3\end{array}$ & $\begin{array}{l}0.57 \\
1.14 \\
2.32\end{array}$ & $\begin{array}{r}3.4 \\
6.8 \\
13.9\end{array}$ \\
\hline
\end{tabular}

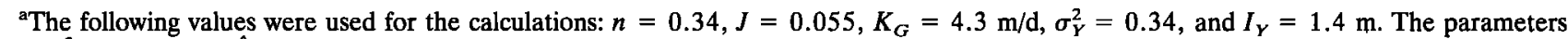
$K_{G}, \sigma_{Y}^{2}, I_{Y}, D_{x}$, and $\hat{U}$ were estimated using geophysical data.

${ }^{b}$ Here, $x$, travel distance; $t$, travel time.

and 200 hours after injection along the same traverse as the estimated hydraulic conductivity section shown in Plate 8a. Plate $8 \mathrm{~b}$ suggests that the injected bromide plume initially travels quickly along the zone interpreted using the tomography data as the main high-conductivity zone. After 48 hours (Plate 8c) the plume has "found" other nearby highconductivity zones and travels within upper and lower highconductivity zones located nominally at the depths of samplers 6 and 12, respectively. After 200 hours the remaining plume mass along this study section is located predominantly within the low conductivity zone, as shown in Plate $2 \mathrm{~d}$. Although the values shown in Plate 8a represent only the means of the estimated probability distribution functions at each location, and while the image is only two-dimensional, this figure suggests that tomographic data can be used qualitatively to estimate the locations of quicker transport along the highconductivity zones and the slower transport along the lowconductivity zones.

In addition to the visual comparison made above, the validity of the tomographic data can also be assessed by using the data to estimate bromide plume spatial moments and then comparing these estimates to moment observations made using bromide breakthrough data. In a homogeneous porous media flow field the velocity determines the rate at which the center of mass of a solute body moves through a saturated system, and dispersion coefficients control the spatial extent over which the solute body is distributed. Assuming steady flow parallel to bedding, the mean flow velocity $U$ was initially estimated using $\hat{U}=K_{G} J / n$, where $J$ is the spatial average of the forced gradient during the tracer test experiment, $n$ is the porosity, and $K_{G}$ is the tomographically obtained geometric mean of the hydraulic conductivity pdf means of the transport study traverse shown in Plate $8 \mathrm{a}$. For our calculation we used $J=$ 0.055 and $n=0.34$ (T. Scheibe, Pacific Northwest National Laboratory, personal communication, 2000). The results of this tomographically obtained velocity estimate are shown in Table 3. Also shown in Table 3 are the measured velocities at the three different times, obtained by dividing the distance that the bromide plume centroid has traveled $(x)$ by the associated transport travel time $(t)$. The location of the centroid was estimated by visual examination of the displays given in Plates $8 \mathrm{~b}-8 \mathrm{~d}$. The low velocity calculated for $t=200$ hours is likely an artifact of the displayed domain size, as sequential examination of all time-lapse breakthrough images clearly displays that the bromide mass that resides in the low-conductivity zone at that time represents only a small portion of the total plume mass. Comparison of the estimated and measured mean flow velocity values indicates that the tomographically obtained value yields an estimate approximately midway between those values associated with plume travel in high-conductivity zones (Plates $8 b$ and $8 c$ ) and that value associated with travel through the low-conductivity zone (Plate 8d). This is expected, as the tomography-obtained velocity estimate was obtained by averaging over the displayed domain, while the velocities calculated at $t=12,48$, and 200 hours are associated with travel in the main high-conductivity zone, outlier high-conductivity zones, and low-conductivity zone, respectively.

To estimate the longitudinal effective dispersion coefficient $D_{x}$ in the direction of flow and parallel to bedding, we use the variance of $\log$ conductivity $\left(\sigma_{Y}^{2} \approx 0.34\right)$ and the integral scale in the mean flow direction $\left(I_{Y, \text { horizontal }} \approx 1.4 \mathrm{~m}\right)$, both estimated using tomographic data as described in section 5.3, with

$$
D_{x}=\sigma_{Y}^{2} I_{Y, \text { honzontal }} \hat{U},
$$

which is given for asymptotic conditions of approximately $U t /$ $I_{Y, \text { horizontal }} \geq 15$ [Dagan, 1989]. For this transport study at 12-200 hours after injection, we are working under preasymp-


However, the expression given in (7) has been used to provide reasonable approximations of plume moments under nonasymptotic conditions [Rubin and Ezzedine, 1997]. The effective longitudinal dispersion coefficient calculated using (7) with the tomographic estimates of variance and integral scale is given in Table 3 .

Finally, we use the calculated dispersion coefficient to estimate length scales associated with the plume. Assuming that the spatial spread of a solute body is controlled by the dispersion coefficient and increases with travel time $t$, we can use the values calculated in (7) to estimate the variance of the bromide plume in the horizontal direction $\sigma_{x}^{2}$ :

$$
\sigma_{x}^{2}=2 D_{x} t
$$

The length of the plume in the flow direction can then be estimated using the standard deviation value calculated from (8). For Gaussian plumes, $99.7 \%$ of the mass is contained within 3 standard deviations from the center of the plume in directions both in front of and behind the center of mass [Domenico and Schwartz, 1990]. We compare, then, the length of the plume envelope estimated from Plates $8 \mathrm{~b}$ and $8 \mathrm{~d}$ with values of 6 standard deviations ( \pm 3 standard deviations) calculated using (8). It is impossible to visually estimate the plume length scale at 200 hours using Plate $8 \mathrm{~d}$, as the displayed domain length is insufficient. However, at 12 hours a portion of the plume has traveled along the main high-conductivity zones to approximately $3.5 \mathrm{~m}$ downgradient from the injection well, and at 48 hours the plume appears to extend downgradient to distances slightly more than the displayed domain length of 
$7 \mathrm{~m}$. Comparison of the plume length scales estimated using geophysical information of 3.4 and $6.8 \mathrm{~m}$, respectively, suggests that the estimated length scales are reasonable compared to the observed scales. Consideration of all estimated length scales suggests that the spatial spread of the solute body increases almost linearly with time. This behavior is in accord with the linear theory of transport developed for conditions of low variability and early times [Dagan, 1989], such as the conditions that exist for this transport study.

This cursory examination of the bromide plume spatial moments illustrates that analysis of the tomographic data led to estimates of transport that were in agreement with observations. This agreement, together with the visual comparison of the tomographically obtained hydraulic estimates and breakthrough data shown in Plate 8 and the cross-validation results of Chen et al. [2001], gives us confidence in our methods for parameter estimation.

\section{Conclusions}

Although previous research suggested that hydrogeological heterogeneity exerts a key influence on field-scale microbial transport [Harvey et al., 1993; Bales et al., 1995, 1997; Natch et al., 1996], no study to date has collected dense enough subsurface characterization data in tandem with a field-scale bacterial transport experiment to allow investigation of the extent of the control. Our study focused on collecting geophysical data across a range of spatial scales at the South Oyster Bacterial Transport Site and using the data to provide hydrogeological characterization information necessary to enable such an assessment.

Multidimensional information obtained from the geophysical data at the Oyster Site was used to guide and assist the field operations, to assist with the interpretation of breakthrough data collected during the bacterial injection experiment, and to constrain the numerical bacterial transport model. At the largest scale, surface GPR data were used to delineate the subregional geology and to select locations for the focus areas. More detailed surface radar data were used to map the key boundaries within the Narrow Channel Focus Area and to position the aerobic flow cell within the area. Tomographic data, collected within the flow cell, were used initially to position the locations of well bore chemical and bacterial tracer injection and multilevel sampling instrumentation. After relationships between the tomographic attributes and hydraulic conductivity had been established, quantitative estimates of hydraulic conductivity pdfs conditioned to well bore flowmeter data were produced. The depth structure contour maps of the key boundaries (from surface GPR data) and the hydraulic conductivity pdf estimates (from radar tomography and flowmeter data) will be used to constrain the numerical bacterial transport flow models that are being designed to help understand bacterial transport at the South Oyster Site [Scheibe et al., 1999, 2001]. At the Oyster Site the tomographic estimates of hydraulic conductivity have been used together with field-scale bacterial transport data to reduce ambiguity associated with interpretation of the breakthrough data. For example, Johnson et al. [2001] found, using the hydraulic conductivity estimates obtained from the tomographic data, that the timing of bacterial breakthrough was controlled by the hydrogeological heterogeneity as opposed to variation in sediment surface or aqueous chemical properties at the Narrow Channel Focus Area.

The conductivity estimates obtained from the tomographic data were subsequently analyzed to estimate structural correlation parameters such as integral scale and anisotropy. We found that the flowmeter and tomographic data produced similar spatial correlation estimates in the vertical direction and that the tomographic data were useful for providing those estimates in the horizontal direction. These spatial correlation parameters will also be used to help to constrain the stochastic numerical transport models. Finally, geostatistical parameter estimates, obtained from the tomographic data, were used to estimate the plume spatial moments. These values were compared with bromide tracer plume velocity and length scales and were found to be reasonable. This favorable comparison, together with visual examination of the breakthrough data compared to the estimated hydraulic conductivity field (Plate 8) and the cross-validation results of Chen et al. [2001], gives us confidence in our tomography-based methods for parameter estimation.

Our study shows that even within the fairly uniform deposits of the Narrow Channel Focus Area, heterogeneities exist that influence conservative chemical tracer transport over lateral distances of a few meters and vertical distances of less than a half meter. Other studies [Johnson et al., 2001] illustrate the importance of the characterization data for interpretation of field-scale bacterial transport data. Although more fieldwork of this nature is necessary to validate the usefulness and costeffectiveness of including geophysical data in the characterization effort, the interpretations presented here suggest that incorporation of geophysical data with limited hydrological data may provide valuable information about the stratigraphy, $\log$ conductivity values, and spatial correlation structure of log conductivity that can be crucial for predicting flow and transport through a system. This type of characterization data, traditionally only obtainable by performing extensive and intrusive hydrological sampling, may help to reduce the ambiguity associated with hydrogeological heterogeneity that is often encountered when interpreting field-scale bacterial breakthrough data. Although our study focused on this specific study site, the characterization approach and methodologies presented here are applicable to other subsurface study sites.

Acknowledgments. This study was supported by the Assistant Secretary for Energy Research, Office of Health and Environmental Research, under the direction of element manager Frank Wobber, and with U.S. Department of Energy contract DE-AC03-76SF00098 to Ernest L. Majer, U.S. Department of Energy contract ER624781010025-0001649 to Donald Swift, and NSF grant EAR 9628306 to Yoram Rubin. We are indebted to Bob Bainer at Lawrence Livermore National Laboratory for lending us the Strataview seismic acquisition system, to the Nature Conservancy for providing the site for this project, to Tim Griffen at Golder Associates for superlative organization of field activities, and to all members of the Oyster Research Group for providing comparative data and fruitful discussions. We thank three anonymous reviewers and Charles Harvey for providing insightful and useful suggestions that helped to improve the manuscript. All computations were carried out at the Center for Computational Seismology (CCS), supported by DOE's office of Basic Energy Sciences, at Lawrence Berkeley National Laboratory.

\section{References}

Ababou, R., and L. Gelhar, Self-similar randomness and spectral conditioning: Analysis of scale effects in subsurface hydrology, in $D y$ namics of Fluids in Hierarchical Porous Media, edited by J. H. Cushman, pp. 393-428, Academic, San Diego, Calif., 1990.

Ang, A., and W. H. Tang, Probability Concepts in Engineering Planning and Design, vol. 1, Basic Prnciples, John Wiley, New York, 1975. 
Bales, R. C., S. Li, K. M. Maguire, M. T. Yahya, C. P. Gerba, and R. W. Harvey, Virus and bacteria transport in a sandy aquifer, Cape Cod, MA, Ground Water, 33(4), 653-661, 1995.

Bales, R. C., S. Li, J. Yeh, M. E. Lenczewski, and C. Gerba, Bacteriophage and microsphere transport in saturated porous media: Forced-gradient experiment at Borden, Ontario, Water Resour. Res., 33(4), 639-648, 1997.

Bracewell, R., The Fourier Transform and Its Applications, McGrawHill, New York, 1965.

Bregman, N. D., R. C. Bailey, and C. H. Chapman, Crosshole seismic tomography, Geophysics, 54(2), 200-215, 1989

Chen, J., S. Hubbard, and Y. Rubin, Estimating the hydraulic conductivity at the South Oyster Site from geophysical tomographic data using Bayesian techniques based on the normal linear regression model, Water Resour. Res., 37(6), 1603-1613, 2001.

Copty, N., and Y. Rubin, A stochastic approach to the characterization of lithofacies from surface seismic well data, Water Resour. Res., 31(7), 1673-1686, 1995.

Copty, N., Y. Rubin, and G. Mavko, Geophysical-hydrogeological identification of field permeabilities through Bayesian updating, $\mathrm{Wa}$ ter Resour. Res., 29(8), 2813-2825, 1993.

Dagan, G., Flow and Transport in Porous Formations, Springer-Verlag, New York, 1989.

Daily, W. D., and A. L. Ramirez, In situ porosity distribution using geophysical tomography, Geophys. Res. Lett., 11(6), 614-616, 1984.

Daily, W., A. Ramirez, D. LaBrecque, and J. Nitao, Electrical resistivity tomography of vadose zone water movement, Water Resour. Res., 28(5), 1429-1442, 1992.

Davis, J., and A. Annan, Ground-penetrating radar for high-resolution mapping of soil and rock stratigraphy, Geophys. Prospect., 37, 531$551,1989$.

DeFlaun, M. F., C. J. Murray, W. Holben, T. Scheibe, A. Mills, T. Ginn, T. Griffin, E. Majer, and J. L. Wilson, Preliminary observations on bacterial transport in a coastal plain aquifer, FEMS Microbiol. Rev., 20, 473-487, 1997.

Domenico, P. A., and F. W. Schwartz, Physical and Chemical Hydrogeology, 824 pp., John Wiley, New York, 1990.

Eppstein, M. J., and D. E. Dougherty, Efficient three-dimensional data inversion: Soil characterization and moisture monitoring from crosswell ground-penetrating radar at a Vermont test site, Water Resour. Res., 34(8), 1889-1900, 1998.

Ezzedine, S., Y. Rubin, and J. Chen, Hydrological-geophysical Bayesian method for subsurface site characterization: Theory and application to LLNL Superfund Site, Water Resour. Res., 35(9), 26712684, 1999.

Freeze, R. A., and J. A. Cherry, Groundwater, 604 pp., Prentice-Hall, Old Tappan, N. J., 1979.

Fuller, M. E., H. Dong, B. J. Mailloux, T. C. Onstott, and M. F. DeFlaun, Examining bacterial transport in intact cores from Oyster Virginia: Effect of sedimentary facies type on bacterial breakthrough and retention, Water Resour. Res., 36(9), 2417-2432, 2000a

Fuller, M. E., S. H. Streger, R. K. Rothmel, B. J. Mailloux, J. A. Hall, T. C. Onstott, J. K. Fredrickson, D. L. Balkwill, and M. F. DeFlaun, Development of a vital fluorescent staining method for monitoring bacterial transport in subsurface environments, Appl. Environ. Microbiol., 66, 4486-4496, $2000 \mathrm{~b}$.

Gardner, W. A., Statistical Spectral Analysis: A Nonprobabilistic Theory, Prentice-Hall, Old Tappan, N. J., 1988.

Gelhar, L. W., Stochastic Subsurface Hydrology, 390 pp., Prentice-Hall, Old Tappan, N. J., 1993.

Green, M., J. Chen, S. Hubbard, E. Majer, and C. Murray, Deriving hydrofacies from lithofacies at the Oyster Virginia Experimental Site, Eos Trans. $A G U, 81(48)$, Fall Meet. Suppl., F184, 2000.

Gritto, R., V. A. Korneev, J. E. Peterson, and L. R. Johnson, The effect of source and receiver coupling on travel time and amplitude inversion results, Eos Trans. $A G U, 78(46)$, Fall Meet. Suppl., F462, 1997.

Harvey, R. W., N. E. Kinner, D. MacDonald, D. W. Metge, and A. Bunn, Role of physical heterogeneity in the interpretation of smallscale laboratory and field observations of bacteria, microbial-sized microsphere, and bromide transport through aquifer sediments, $\mathrm{Wa}$ ter Resour. Res., 29(8), 2713-2721, 1993.

Hubbard, S., E. Majer, J. Geller, J. Peterson, and B. Parsons, Permeability estimation using geophysical data, Eos Trans. $A G U, 77(46)$, Fall Meet. Suppl., F220, 1996.

Hubbard, S. S., Y. Rubin, and E. Majer, Ground-penetrating-radar assisted saturation and permeability estimation in bimodal systems, Water Resour. Res., 33(5), 971-990, 1997.

Hubbard, S., Y. Rubin, and E. Majer, Spatial correlation structure estimation using geophysical data, Water Resour. Res., 35(6), 1809$1825,1999$.

Hyndman, D. W., and S. M. Gorelick, Estimating lithologic and transport properties in three dimensions using seismic and tracer data: The Kesterson Aquifer, Water Resour. Res., 32(9), 2659-2670, 1996.

Hyndman, D. W., J. M. Harris, and S. M. Gorelick, Coupled seismic and tracer test inversion for aquifer property characterization, Water Resour. Res., 30(7), 1965-1977, 1994.

Hyndman, D. W., J. M. Harris, and S. M. Gorelick, Inferring the relation between seismic slowness and hydraulic conductivity in heterogeneous aquifers, Water Resour. Res., 36(8), 2121-2132, 2000.

Johnson, W. P., et al., Ferrographic tracking of bacterial transport in the field at the Narrow Channel Focus Area, Oyster, VA, Environ. Sci. Technol., 35, 182-191, 2001.

Knight, R., J. Rea, P. Tercier, and H. Jol, Geostatistical analysis of ground penetrating radar data: A means of characterizing the correlation structure of sedimentary units, Eos Trans. $A G U, 77(46)$, Fall Meet. Suppl., F237, 1996.

Knight, R., P. Tercier, and H. Jol, The role of ground penetrating radar and geostatistics in reservoir description, Leading Edge, 16(11), 1576-1583, 1997.

Knoll, M., R. Knight, and E. Brown, Can accurate estimates of permeability be obtained from measurement of dielectric properties? paper presented at SAGEEP Annual Meeting, Orlando, Fla., April 23-26, 1995.

Lunne, T., P. K. Robertson, and J. J. M. Powell, Cone Penetration Testing in Geotechnical Practice, Blackie Acad. and Prof., New York, 1997.

Marion, D., Acoustical, mechanical and transport properties of sediments and granular materials, Ph.D. thesis, Stanford Univ., Stanford, Calif., 1990.

Matheron, G., The intrinsic random functions and their applications, Adv. Appl. Probab., 5, 438-468, 1973.

McKenna, S. A., and E. P. Poeter, Field example of data fusion in site characterization, Water Resour. Res., 31(12), 3229-3240, 1995.

Mixon, R. B., Stratigraphic and geologic framework of Upper Cenozoic deposits in the Southern Delmarva Peninsula, U.S. Geol. Surv. Prof. Pap., 1067-G, 53 pp., 1985.

Molz, F. J., and S. C. Young, Development and application of borehole flowmeters for environmental assessment, Log Anal., 3, 13-23, 1993.

Molz, F. J., G. K. Boman, S. C. Young, and W. R. Waldrop, Borehole flowmeters: Field application and data analysis, J. Hydrol., 163, 347371, 1994.

Natch, A., C. Keel, J. Troxler, M. Zala, N. von Albertini, and G. Defago, Importance of preferential flow and soil management in vertical transport of biocontrol strain of Pseudomonas fluorescens in structured field soil, Appl. Environ. Microbiol., 2, 33-40, 1996.

Peterson, J. E., Jr., The application of algebraic reconstruction techniques to geophysical problems, Ph.D. thesis, Dep. of Geol. Sci, Univ. of Calif., Berkeley, 1986.

Peterson, J. E., Pre-inversion processing and analysis of tomographic radar data, J. Environ. Eng. Geophys., 6(1), 1-18, 2001.

Peterson, J. E., B. N. Paulsson, and T. V. McEvilly, Applications of algebraic reconstruction techniques to crosshole seismic data, Geophysics, 50, 1566-1580, 1985.

Poeter, E., W. L. Wingle, and S. A. McKenna, Improving groundwater project analysis with geophysical data, Leading Edge Explor., 16(11), 1075-1681, 1997.

Ratkowsky, D. A., Nonlinear Regression Modeling, Marcel Dekker, New York, 1983.

Rea, J., and R. Knight, Geostatistical analysis of ground penetrating radar data: A means of describing spatial variations in the subsurface, Water Resour. Res., 34(3), 329-340, 1998.

Rector, J. W., III (Ed.), Crosswell methods, Geophysics, 60, 627-920, 1995.

Robertson, P. K., R. G. Campanela, D. Gillespie, and J. Greig, Use of piezometer cone data, in Proceedings of the ASCE Specialty Conference In Situ '86: Use of In Situ Tests in Geotechnical Engineering, pp. 1263-1280, Am. Soc. of Civ. Eng., Reston, Va., 1986.

Rubin, Y., and S. Ezzedine, The travel times of solutes at the Cape Cod Tracer Experiment: Data analysis, modeling, and structural parameter inference, Water Resour. Res., 33(7), 1537-1547, 1997.

Rubin, Y., G. Mavko, and J. Harris, Mapping permeability in hetero- 
geneous aquifers using hydrological and seismic data, Water Resour. Res., 28(7), 1192-1800, 1992.

Rubin, Y., S. Hubbard, M. Cushey, and A. Wilson, Aquifer characterization, in Manual of Groundwater Hydrology, pp. 10.1-10.68, CRC Press, Boca Raton, Fla., 1998.

Scheibe, T. D., Y. Chien, T. Ginn, C. Murray, and S. S. Hubbard, Heterogeneity characterization for field-scale bacterial transport modeling, Eos Trans. AGU, 80(17), Spring Meet. Suppl., S115, 1999.

Scheibe, T. D., Y. Chien, and J. Radtke, Use of quantitative models to design microbial transport experiments in a sandy aquifer, Ground Water, 39(2), 210-222, 2001.

Vail, P. R., R. M. Mitchum, R. G. Todd, J. M. Widmier, S. Thompson, J. B. Sangree, J. N. Bubb, and W. G. Hatlelid, Seismic stratigraphy and global changes in sea level, AAPG Mem., 26, 49-212, 1977.

Vasco, D. W., J. E. Peterson Jr., and E. L. Majer, A simultaneous inversion of seismic traveltimes and amplitudes for velocity and attenuation, Geophysics, 61, 1738-1757, 1996.
J. Chen and Y. Rubin, Department of Civil and Environmental Engineering, University of California, Berkeley, Berkeley, CA 94720. (jschen@ce.berkeley.edu; rubin@ce.berkeley.edu)

S. S. Hubbard, E. Majer, J. Peterson, and K. Williams, Earth Science Division, Lawrence Berkeley National Laboratory, 1 Cyclotron Road, MS 90-1116, Berkeley, CA 94720. (sshubbard@lbl.gov)

B. Mailloux, Department of Geosciences, Princeton University, 114 Guyot Hall, Princeton, NJ 08544. (mailloux@princeton.edu)

D. J. Swift, Department of Ocean, Earth and Atmospheric Sciences, Old Dominion University, Norfolk, VA 23529. (dswift@odu.edu)

(Received August 1, 2000; revised January 19, 2001; accepted April 9, 2001.) 